\title{
19. PRELIMINARY ORGANIC ANALYSES OF DSDP CORES, LEGS 12 AND $13^{1}$
}

\author{
Bernd R. Simoneit and A. L. Burlingame, Space Sciences Laboratory, University of California, Berkeley
}

\begin{abstract}
Organic carbon-rich samples from Sites 113 and 114 of DSDP Leg 12 and Sites 128,130 , and 134 of DSDP Leg 13 were analyzed. The solvent soluble organic matter consisted mainly of alkanes for all samples. The samples from Sites 112,114 , and 128 exhibited an alkane distribution with a strong odd/even predominance mainly of terrigenous derivation. The fatty acids were found in lesser amounts with an even/odd predominance and appear to be about half marine and half terrigenous in origin for all the samples analyzed. Steroidal and triterpenoidal compounds were minor components of all the samples and are of both marine and terrigenous origin.

Isoprenoidal ketones were found in this sample suite as the compounds 6,10,14-trimethylpentadecan-2-one $\left(\mathrm{C}_{18}\right)$ and 6,10 -dimethylundecan-2-one $\left(C_{13}\right)$. The $C_{18}$ homolog is by far the more abundant ketone and is probably derived from phytol or chlorophyll by oxidative diagenesis. A compound of molecular weight 554 and composition $\mathrm{C}_{40} \mathrm{H}_{74}$ was found in the sample from Site 114. Its possible structure is $m$ - or $p$-(4,8,12-trimethyltridecyl-1,-5,9,13-tetramethyltetradecyl)benzene, which may be a diagenetic product from a Diels-Alder dimer of phytadiene, derived from phytol.
\end{abstract}

\section{INTRODUCTION}

The samples analyzed from DSDP Leg 12 are derived from Site 112 in the middle of the Labrador Sea and Site 114 near the crest of the Reykjanes Ridge, on its eastern flank. Site $112\left(54^{\circ} 1.0^{\prime} \mathrm{N}, 46^{\circ} 36.2^{\prime} \mathrm{W}\right)$ is in a water depth of 3,667 meters and Site $114\left(59^{\circ} 56^{\prime} \mathrm{N}, 26^{\circ} 48^{\prime} \mathrm{W}\right)$ is under 1,937 meters of water (Laughton et al., 1970). Sample 12-112-11-4,10-99 cm consists of silty marl ooze, deposited under high sedimentation rates $(1.3 \mathrm{~cm} / 1,000$ years $)$ by bottom currents and is of middle Oligocene age (approximately $32 \times 10^{6}$ years B.P.) (Laughton et al., 1970). Sample 12-114-5-5, 80-140 cm consists of silty clays deposited under abnormally high sedimentation rates by bottom contour currents and is of middle Pliocene age (approximately $6 \times 106$ years B.P.) (Laughton et al., 1970).

The samples analyzed from Leg 13 are derived from Sites 128 (Ionian Basin), 130 (Levantine Basin), and 134 (Balearic Basin) all in the Mediterranean Sea. Site 128 $\left(35^{\circ} 42.6^{\prime} \mathrm{N}, 22^{\circ} 28.1^{\prime} \mathrm{R}\right)$ is in a water depth of 4,640 meters; Site $130\left(33^{\circ} 36.3^{\prime} \mathrm{N}, 27^{\circ} 52.0^{\prime} \mathrm{E}\right)$ is in 2,980 meters of water; and Site $134\left(39^{\circ} 11.8^{\prime} \mathrm{N}, 07^{\circ} 18.0^{\prime} \mathrm{E}\right)$ is in 2,868 meters of water (Ryan et al., 1970). Samples 13-128-3-4, $122-124 \mathrm{~cm}$ and $13-128-3-5,38-40 \mathrm{~cm}$ consist of gray marl ooze with some foraminifera and terrigenous debris with clay. Their age is Pleistocene (Ryan et al., 1970). Sample 13-130-1-2, 123-125 cm consists of nannoplankton ooze and terrigenous black clay. Pyrites and $\mathrm{H}_{2} \mathrm{~S}$ were

\footnotetext{
${ }^{1}$ Research supported by the Oceanographic Section, National Science Foundation, NSF Grant GA-24214.
}

encountered in the dark sediment (Ryan et al., 1970) and the sediment is of Pleistocene age. Sample 13-134-5-2, $77.79 \mathrm{~cm}$ consists of gray nannoplankton ooze and is of middle Pliocene age (Ryan et al., 1970).

These particular small samples (approximately $5 \mathrm{~g}$ ) were chosen from areas in the recovered cores with relatively high organic carbon content in order to minimize organic contamination from the core tube material.

\section{EXPERIMENTAL}

High resolution mass spectrometric analyses of the benzene/methanol or toluene/methanol soluble extracts were carried out on a GEC-AEI MS-902 mass spectrometer on-line to an XDS Sigma 7 computer (described by Burlingame, 1968 and 1970; Burlingame et al., 1970). The samples were introduced via a ceramic direct inlet probe into the ion source, operated at the following conditions: resolution 10,000 ; ionizing current $500 \mu \AA$; ionizing voltage $50 \mathrm{eV}$; and temperature $200^{\circ}$ to $220^{\circ} \mathrm{C}$. The scan rate was 16 seconds per decade with a clock rate of $24 \mathrm{kHz}$. Multiple scans were taken during each analysis and then sum averaged together during data reduction. Selected high resolution mass spectral data are presented as heteroatomic plots (Burlingame and Smith, 1968) in various figures in the text.

Analyses using gas chromatography-mass spectrometry were carried out on a modified Varian MAT Model 311 GC/MS linked on-line to an XDS Sigma 2 computer (Smith et al., 1971). The GC conditions used in the GC/MS analyses are the same as cited in the respective $\mathrm{GC}$ figure legends, and the mass spectrometric and computer operating parameters are as reported (Smith et al., 1971). Certain mass spectra from the various $\mathrm{GC} / \mathrm{MS}$ analyses were 
identified by use of a compound classifier (Smith, 1972; Chang et al., in preparation).

Gas chromatographic analyses were carried out using a Perkin-Elmer Model 900 gas chromatograph fitted with a flame ionization detector and operating under the conditions stated in the figure legends.

All solvents used, e.g., toluene, benzene, methanol, and $n$-heptane, were Mallinckrodt Nanograde quality. The toluene, benzene, and methanol were redistilled in an all-glass apparatus prior to use.

All the samples were dried under vacuum $\left(60^{\circ} \mathrm{C}\right.$ and 25 $\mathrm{cm} \mathrm{Hg}$ pressure) and then powdered using a mortar and pestle. The dry weights averaged $3 \mathrm{~g}$ for the small samples (Leg 13) and $150 \mathrm{~g}$ for the larger samples (Leg 12). The powders were then extracted in an all-glass Soxhlet apparatus for 3 to 5 days. After filtration through a fine glass frit, the extracts were concentrated on a rotary evaporator (bath at $30^{\circ}$ to $40^{\circ} \mathrm{C}$ ) and then repartitioned into a heptane-diethyl ether soluble fraction and toluene or benzene-methanol soluble fraction. These fractions were not further separated and were subjected directly to GC and mass spectrometric analyses.

\section{RESULTS}

The solvent extract yields from the core samples are listed in Table 1 and the elemental analyses of these samples are found in Table 2.

\section{Site 112}

The GC traces for the extract fractions from Sample 12-112-11-4, 10-99 cm are shown in Figure 1. The salient features of the GC/MS analysis of the heptane-ether soluble fraction appear in Figure 2 and are summarized in Table 3. The major component of the mixture is the contaminant dioctyl 2.3-dimethylsuccinate (cf. scan 94 in Figure 2a, base peak at m/e 129 shown in Figure 2d) (Simoneit et al., $1973 \mathrm{~b})$. The major homologous series is comprised of normal alkanes, $\mathrm{C}_{n} \mathrm{H}_{2 n+2}$ (cf. Figure $2 \mathrm{~b}$ ), ranging from $n=$ 17-35 and maximizing at $n=29$, with odd/even predominance above $n=26$. The spectrum of $n$-hentriacontane appears in Figure $2 \mathrm{~g}$. Carboxylic acids, as the methyl esters, are present in lower amounts. The series, $\mathrm{C}_{n} \mathrm{H}_{2 n} \mathrm{O}_{2}$ (cf. Figure 2c), ranges from $n=14-31$ maximizing at $n=18$ and exhibiting an even/odd predominance. These esters probably formed from the free acids during Soxhlet extraction by clay catalyzed esterification with the methanol extraction solvent (Simoneit et al., in press). This reaction was shown to proceed with terrigenous sediments (Arpino and Ourisson, 1971). Other contaminants from core tube material and plasticizers are minor, with phthalate esters predominating (cf. base peak m/e 149 in Figure 2e). The group of peaks at scans 100 to 110 (cf. Figure 2e) are due to various isomers of dioctyl phthalate. Two other minor lower weight constituents are pristane and 6,10,14-trimethylpentadecan-2-one. The latter compound has a base peak of $\mathrm{m} / \mathrm{e} 58$ (cf. Figure 2d). The scan 88 spectrum (cf. Figure $2 f$ ) is an unknown compound of probably molecular weight 274 , eluting just after methyl nonadecanoate and it is the third most abundant component of the mixture. Steranes, sterones, and triterpanes were present at trace levels only.

The major components of the benzene and methanol soluble fraction (cf. Figure $1 \mathrm{~b}$ ) are carboxylic acid methyl esters, $\mathrm{C}_{n} \mathrm{H}_{2 n} \mathrm{O}_{2}$, ranging from $n=11-19$ and the contaminant dioctyl 2.3-dimethylsuccinate (Simoneit et al., 1973b).

\section{Site 114}

The GC traces for the extract fractions from samples 12-114-5-5, 80-140 $\mathrm{cm}$ are shown in Figure 3 and the salient features of the GC/MS data of the heptane/ether soluble fraction appear in Figure 4; similar data for the benzene and methanol soluble fraction are shown in Figure 5. The results of the GC/MS analysis of the heptane/ether fraction appear in Figure 4; similar data for the benzene and methanol soluble fraction are shown in Figure 5. The results of the GC/MS analysis of the heptane/ether fraction are summarized in Table 3 . The major components are

TABLE 1

DSDP Core Sample Extracts, Legs 12 and 13

\begin{tabular}{|c|c|c|c|c|c|}
\hline Sample & $\begin{array}{c}\text { Depth Below } \\
\text { Sea Floor } \\
(\mathrm{m})\end{array}$ & $\begin{array}{c}\text { Approximate } \\
\text { Age }\end{array}$ & $\begin{array}{c}\text { Organic } \\
\text { Carbon } \\
\text { \%a }\end{array}$ & $\begin{array}{c}\text { Heptane/ } \\
\text { Ether } \\
\text { Extract } \\
\%\end{array}$ & $\begin{array}{c}\text { Benzene/ } \\
\text { Methanol } \\
\text { Extract } \\
\%\end{array}$ \\
\hline $\begin{array}{l}12-112-11-4, \\
10-99 \mathrm{~cm}\end{array}$ & 329 & $\begin{array}{l}\text { Middle } \\
\text { Oligocene }\end{array}$ & 0.30 & 0.005 & 0.134 \\
\hline $\begin{array}{l}12-114-5-5 \\
80-140 \mathrm{~cm}\end{array}$ & 507 & $\begin{array}{l}\text { Middle } \\
\text { Pliocene }\end{array}$ & 0.15 & 0.070 & 0.112 \\
\hline $\begin{array}{l}13-128-3-4 \\
122-124 \mathrm{~cm}\end{array}$ & 84.8 & Pleistocene & 2.8 & 0.13 & 1.09 \\
\hline $\begin{array}{l}13-128-3-5 \\
38-40 \mathrm{~cm}\end{array}$ & 85.4 & Pleistocene & 2.7 & 0.16 & 1.34 \\
\hline $\begin{array}{l}13-130-1-2 \\
123-125 \mathrm{~cm}\end{array}$ & 15.6 & Pleistocene & 3.0 & 0.12 & 0.63 \\
\hline $\begin{array}{l}13-134-5-2, \\
77-79 \mathrm{~cm}\end{array}$ & 262.3 & $\begin{array}{l}\text { Middle } \\
\text { Pliocene }\end{array}$ & 2.5 & 0.015 & 1.010 \\
\hline
\end{tabular}

aData supplied by G. Bode, DSDP staff. 
TABLE 2

Elemental Analyses of DSDP Core Samples from Legs 12 and 13

\begin{tabular}{|c|c|c|c|c|c|c|c|}
\hline \multicolumn{2}{|c|}{ Sample } & $\begin{array}{c}\text { Total } \\
\text { Carbon } \\
\%\end{array}$ & $\begin{array}{c}\text { Hydrogen } \\
\%\end{array}$ & $\begin{array}{c}\text { Nitrogen } \\
\%\end{array}$ & $\begin{array}{c}\text { Sulfur } \\
\%\end{array}$ & $\begin{array}{c}\text { Residue } \\
\%\end{array}$ & $\begin{array}{c}\text { Oxygen } \\
\% \text { a }\end{array}$ \\
\hline \multirow[t]{2}{*}{$12-112-11-4,10-99 \mathrm{~cm}$} & Dried & 4.60 & 0.77 & 0.02 & 0.04 & 78.9 & 15.63 \\
\hline & Extracted & 5.32 & 0.88 & 0.11 & 0.03 & 89.5 & 4.16 \\
\hline \multirow[t]{2}{*}{$12-114-5-5,80-140 \mathrm{~cm}$} & Dried & 2.78 & 0.95 & 0.28 & 0.15 & 81.1 & 14.84 \\
\hline & Extracted & 2.99 & 1.14 & 0.18 & 0.25 & 88.0 & 7.44 \\
\hline $13-128-3-4,122-124 \mathrm{~cm}$ & Extracted & 8.13 & 0.79 & - & - & 75.9 & 15.18 \\
\hline $13-128-3-5,38-40 \mathrm{~cm}$ & Extracted & 5.74 & 0.78 & - & - & 82.9 & 10.58 \\
\hline $13-130-1-2,123-125 \mathrm{~cm}$ & Extracted & 8.88 & 0.73 & - & - & 72.3 & 18.09 \\
\hline \multirow[t]{2}{*}{$13-134-5-2,77-79 \mathrm{~cm}$} & Dried & 4.07 & 0.69 & - & - & 81.4 & 13.84 \\
\hline & Extracted & 4.19 & 0.66 & - & - & 81.3 & 13.85 \\
\hline
\end{tabular}

aDetermined by difference.

normal alkanes, $\mathrm{C}_{n} \mathrm{H}_{2 n+2}$, ranging from $n=17-33$ with an odd/even predominance above $n=20$ and maximizing at $n$ $=27$ (cf. Figure 4b). Lower amounts of carboxylic acids are present as the methyl esters. The series, $\mathrm{C}_{n} \mathrm{H}_{2 n} \mathrm{O}_{2}$, ranges from $n=15-27$ with a maximum at $n=24$ and a slight even/odd predominance (cf. Figure 4c). The major polycyclic compound series found present are the triterpanes, $\mathrm{C}_{n} \mathrm{H}_{2 n-10}$, ranging from $n=30-32$ and $\mathrm{C}_{n} \mathrm{H}_{2 n-8}$ for $n=30$. These compounds exhibit a base peak at $\mathrm{m} / \mathrm{e}$ 191, Structure I (cf. Figure 4e) in the mass spectra

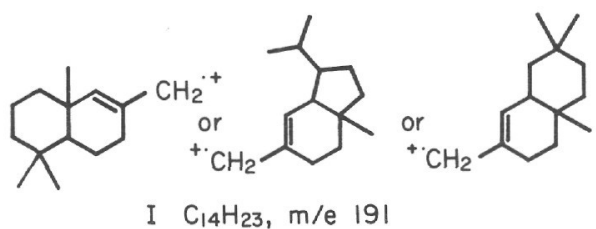

and have strong molecular ions as well as loss of $\mathrm{CH}_{3}$ radical from the molecular ion. Minor amounts of sterones, $\mathrm{C}_{n} \mathrm{H}_{2 n-8} \mathrm{O}$ for $n=27$ and 28 , probably cholestanone (Structure II) and ergostanone (Structure III), were discerned from the strong peaks at $\mathrm{m} / \mathrm{e} 231$ (Structure IV-cf. Figure 4f), $\mathrm{M}-\mathrm{CH}_{3}$ and the respective molecular ions. The sterane series $\mathrm{C}_{n} \mathrm{H}_{2 n-8}$ was present in minor
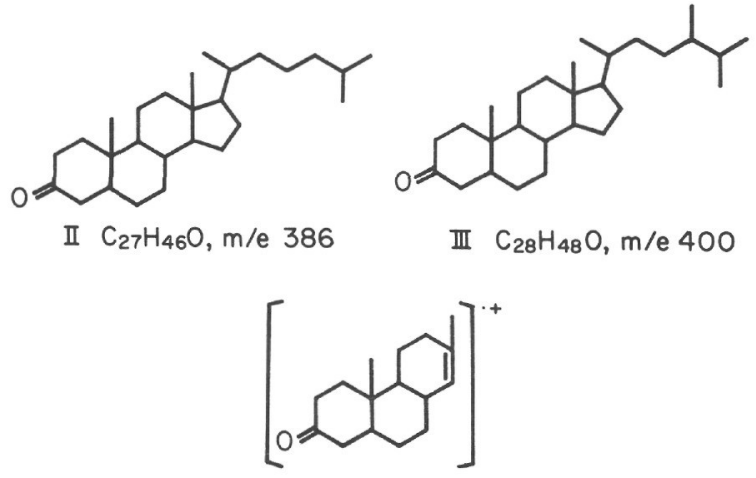

IV $\mathrm{C}_{16} \mathrm{H}_{23} \mathrm{O}, \mathrm{m} / \mathrm{e} 231$

amounts for $n=27-29$. Perylene (Structure V) is a major component as can be seen from the sum plot of the molecular ion (Figure 4g) which maximizes at scan 204.

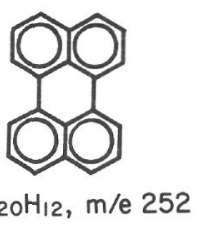

The isoprenoid ketone, 6,10,14-trimethylpentadecan-2-one (Structure VI), is again found in significant amounts along

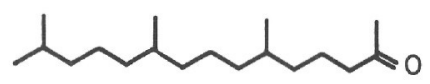

DI $\mathrm{C}_{18} \mathrm{H}_{36} \mathrm{O}, \mathrm{m} / \mathrm{e} 268$

with phytane, but no pristane. An unknown compound, probably with a molecular weight of 382 and a base peak at $\mathrm{m} / \mathrm{e} 115$ (cf. Figure 4i), maximizes at scan 175. This molecule has also been found in Leg 14 samples (Simoneit et al., 1973b). A compound of molecular weight 554 (cf. Figure 4h) appears in scans 274 to 282 (the summed spectrum of scans 272 to 283 is shown in Figure 4j). The spectra are all of mixtures of compounds, mainly the 554 species and a series of triterpanes ranging in molecular weight from m/e 406 to 414 and $\mathrm{m} / \mathrm{e} 422$ to 428 . An example of a possible structure for the $\mathrm{m} / \mathrm{e} 554$ compound is $m$ - or $p$-(4,8,12-trimethyltridecyl-1,5,9,13-tetramethyltetradecyl)benzene (Structure VII). The major fragment

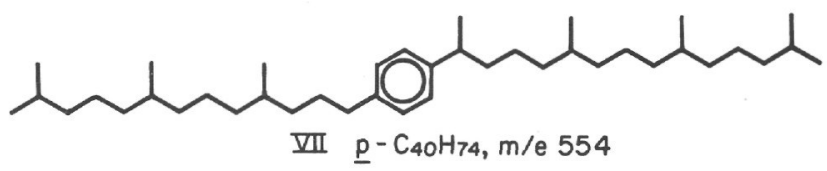

ions of this compound are indicated in Structure VIII and these peaks are found in the data. The synthesis of this

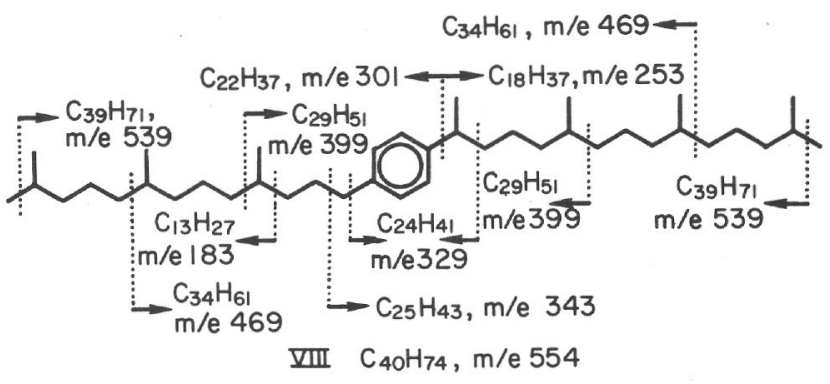




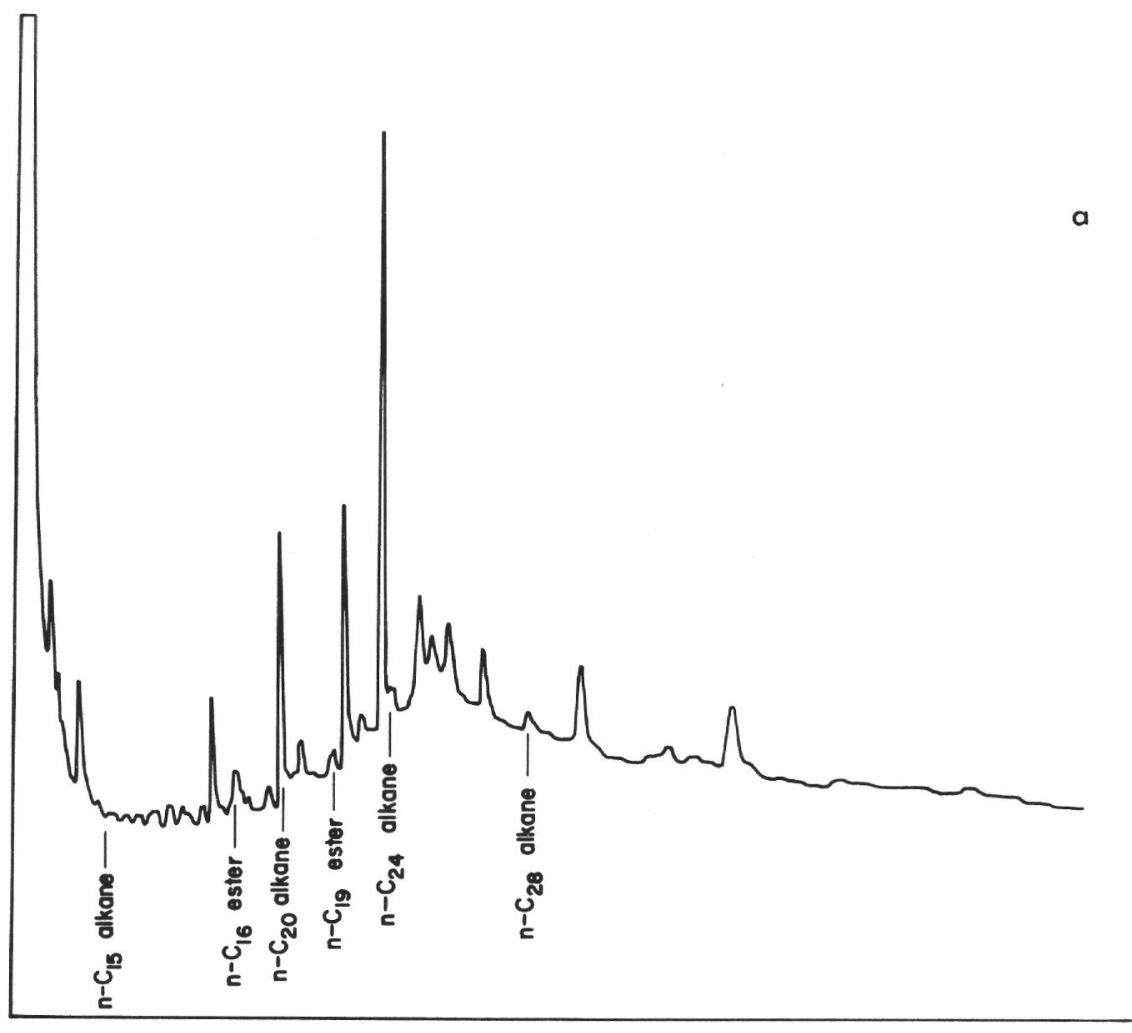

TIME

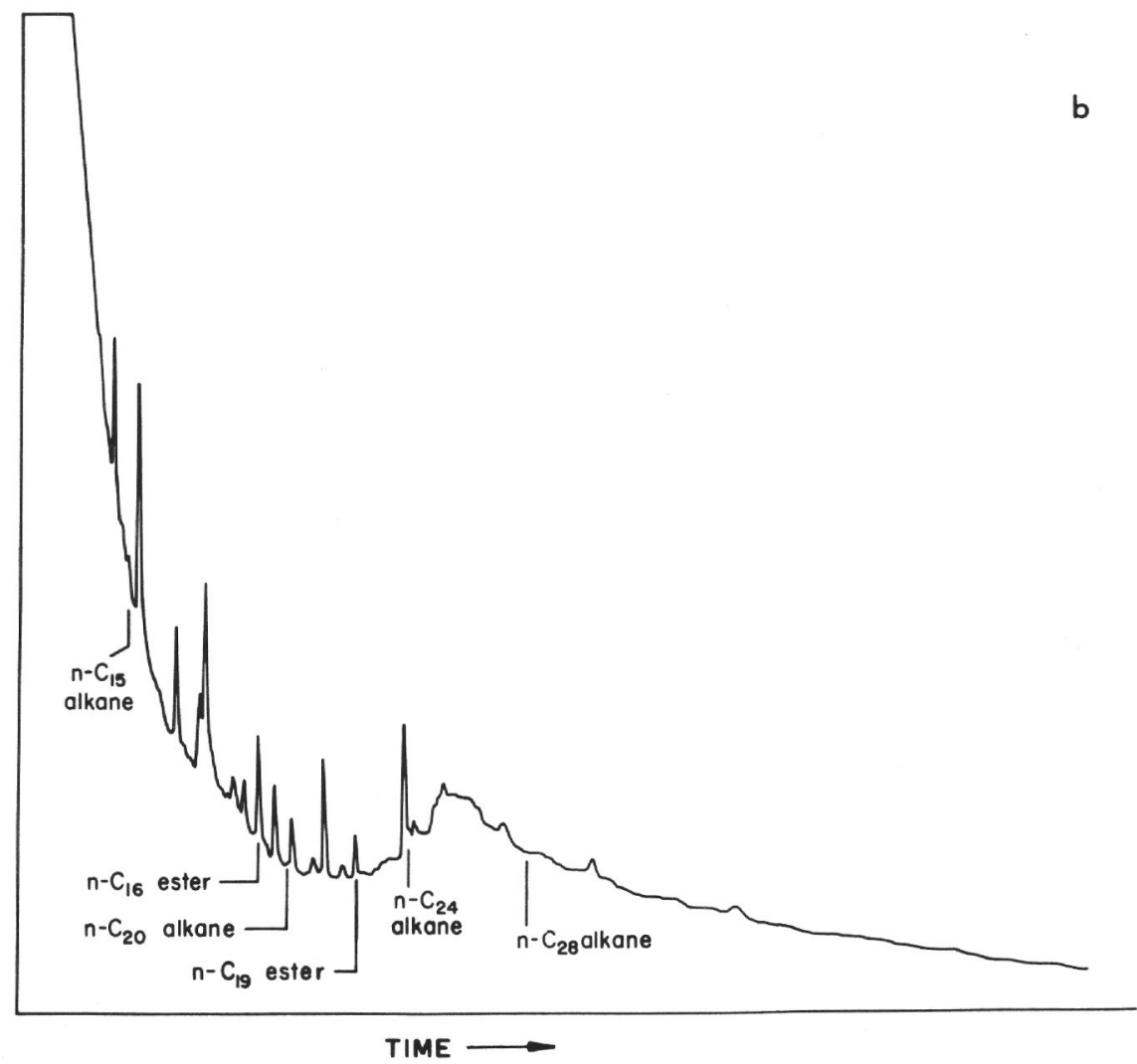

Figure 1. (a) GC trace of the heptane-ether soluble fraction from the exhaustive extract of Sample 12-112-11-4, 10-99 cm, (b) GC trace of the benzene and methanol soluble fraction from the exhaustive extract of Sample 12-112-11-4, 10-99 cm. / GC conditions: $10 \mathrm{ft} \times 1 / 8 \mathrm{in}$. stainless steel column, packed with $3 \%$ OV-1 on 100-200 mesh Gaschrom Q, programmed from $150^{\circ}$ to $275^{\circ} \mathrm{C}$ at $6^{\circ} / \mathrm{min}$ and using He carrier gas at $60 \mathrm{ml} / \mathrm{min}$ ) 
$\bullet$

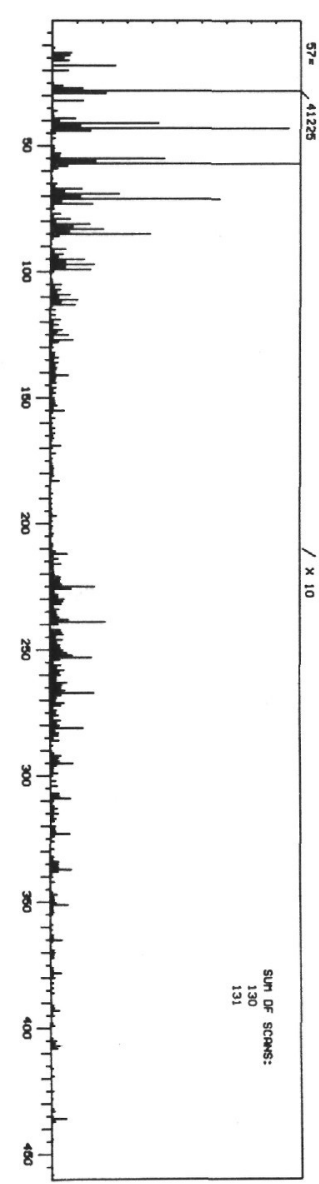

Figure 2. GC/MS data for the total heptane-ether soluble extract fraction from Sample 12-112-11-4, 10-99 cm (GC conditions as cited in Figure 1 b). (a) total ionization sum plot, (b) m/e 43 and m/e 57 sum plot, (c) m/e 74 sum plot, (d) m/e 58 and m/e 129 sum plot, (e) m/e 149 sum plot, (f) mass spectrum scan 88 (unknown-MW 274), (g) summed mass spectrum scans 130 and 131 (n-hentriacontane, MW 436).
Q

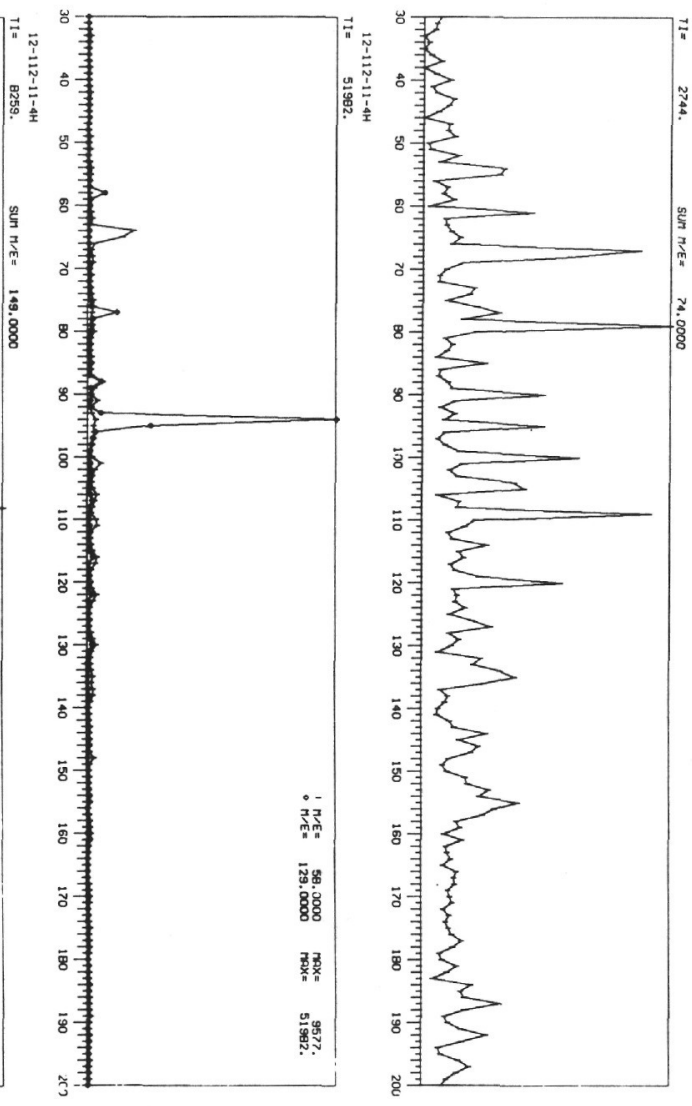

$\sigma$

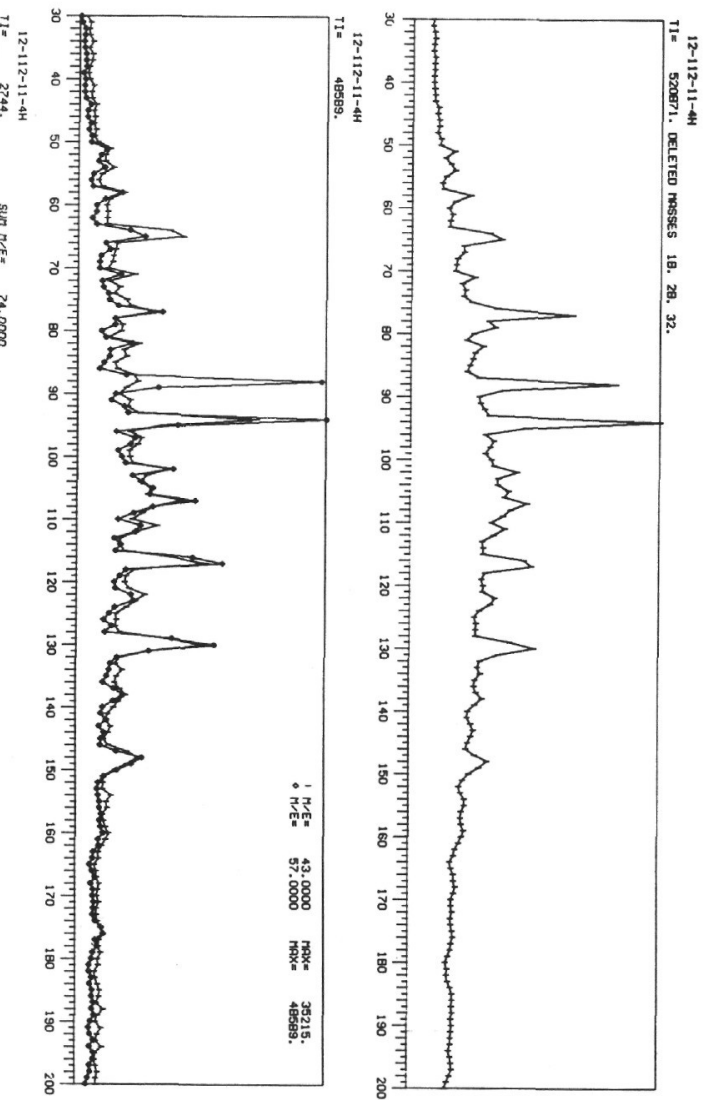


TABLE 3

Major Components of the Heptane-Ether Soluble Extracts from Core Samples of DSDP Leg 12, Determined by GC/MS

\begin{tabular}{|c|c|c|c|c|}
\hline \multirow[b]{3}{*}{ Compound Name } & & & \multicolumn{2}{|c|}{ Sample } \\
\hline & & & 12-112-11-4 & $12-114-5-5$ \\
\hline & \multicolumn{2}{|c|}{$\begin{array}{l}\text { Composition and } \\
\text { Molecular Weight }\end{array}$} & $\begin{array}{l}\text { Spectrum Scan No. } \\
\text { (cf. Fig. 2a) }\end{array}$ & $\begin{array}{l}\text { Spectrum Scan No. } \\
\text { (cf. Fig. 4a) }\end{array}$ \\
\hline Heptadecane $^{b}$ & $\mathrm{C}_{17} \mathrm{H}_{36}$ & 240 & 51 & n.d. \\
\hline Methyl myristate & $\mathrm{C}_{15} \mathrm{H}_{30} \mathrm{O}_{2}$ & 242 & 54 & 130 \\
\hline Pristane & $\mathrm{C}_{19} \mathrm{H}_{40}$ & 268 & 58 & n.d. \\
\hline Methyl pentadecanoate $b$ & $\mathrm{C}_{16} \mathrm{H}_{32} \mathrm{O}_{2}$ & 256 & 61 & 138 \\
\hline $\begin{array}{l}\text { 6,10,14-trimethyl- } \\
\text { pentadecan-2-one }\end{array}$ & $\mathrm{C}_{18} \mathrm{H}_{36} \mathrm{O}$ & 268 & 64 & 139 \\
\hline Phytane & $\mathrm{C}_{20} \mathrm{H}_{42}$ & 282 & n.d. & 141 \\
\hline Nonadecane & $\mathrm{C}_{19} \mathrm{H}_{40}$ & 268 & 65 & 143 \\
\hline Methyl palmitate & $\mathrm{C}_{17} \mathrm{H}_{34} \mathrm{O}_{2}$ & 270 & 66 & 145 \\
\hline Dibutyl phthalate ${ }^{c}$ & $\mathrm{C}_{16} \mathrm{H}_{22} \mathrm{O}_{4}$ & 278 & 67 & n.d. \\
\hline Dibutyl suberated & $\mathrm{C}_{16} \mathrm{H}_{30} \mathrm{O}_{4}$ & 286 & n.d. & 149 \\
\hline Eicosane & $\mathrm{C}_{20} \mathrm{H}_{42}$ & 282 & 71 & 150 \\
\hline Methyl margarate & $\mathrm{C}_{18} \mathrm{H}_{36} \mathrm{O}_{2}$ & 284 & 73 & 153 \\
\hline Dibutyl azelated & $\mathrm{C}_{17} \mathrm{H}_{32} \mathrm{O}_{4}$ & 300 & 77 & 156 \\
\hline Heneicosane & $\mathrm{C}_{21} \mathrm{H}_{44}$ & 296 & 78 & 158 \\
\hline Methyl stearate & $\mathrm{C}_{19} \mathrm{H}_{38} \mathrm{O}_{2}$ & 298 & 79 & 159 \\
\hline Dibutyl sebacated & $\mathrm{C}_{18} \mathrm{H}_{34} \mathrm{O}_{4}$ & 314 & 81 & 161 \\
\hline Docosane & $\mathrm{C}_{22} \mathrm{H}_{46}$ & 310 & 82 & 166 \\
\hline Methyl nonadecanoate & $\mathrm{C}_{20} \mathrm{H}_{40} \mathrm{O}_{2}$ & 312 & 85 & 166 \\
\hline Unknown & - & 274 & 88 & n.d. \\
\hline Tricosane & $\mathrm{C}_{23} \mathrm{H}_{48}$ & 324 & 89 & 171 \\
\hline Methyl arachidate & $\mathrm{C}_{21} \mathrm{H}_{42} \mathrm{O}_{2}$ & 326 & 90 & 175 \\
\hline Unknown & - & 382 & n.d. & 175 \\
\hline Tetracosane & $\mathrm{C}_{24} \mathrm{H}_{50}$ & 338 & 93 & 176 \\
\hline $\begin{array}{l}\text { Dioctyl 2,3-dimethyl- } \\
\text { succinated }\end{array}$ & $\mathrm{C}_{22} \mathrm{H}_{42} \mathrm{O}_{4}$ & 370 & 94 & 177 \\
\hline Methyl heneicosanoate & $\mathrm{C}_{22} \mathrm{H}_{44} \mathrm{O}_{2}$ & 340 & 95 & 178 \\
\hline Pentacosane & $\mathrm{C}_{25} \mathrm{H}_{52}$ & 352 & 97 & 183 \\
\hline Methyl behenate & $\mathrm{C}_{23} \mathrm{H}_{46} \mathrm{O}_{2}$ & 354 & 100 & 184 \\
\hline Hexacosane & $\mathrm{C}_{26} \mathrm{H}_{54}$ & 366 & 102 & 188 \\
\hline Dioctyl phthalate $\mathrm{c}$ & $\mathrm{C}_{24} \mathrm{H}_{38} \mathrm{O}_{4}$ & 390 & 104 & n.d. \\
\hline Methyl tricosanoate & $\mathrm{C}_{24} \mathrm{H}_{48} \mathrm{O}_{2}$ & 368 & 105 & 189 \\
\hline Heptacosane & $\mathrm{C}_{27} \mathrm{H}_{56}$ & 380 & 107 & 194 \\
\hline Methyl lignocerate & $\mathrm{C}_{25} \mathrm{H}_{50} \mathrm{O}_{2}$ & 382 & 109 & 195 \\
\hline Octacosane & $\mathrm{C}_{28} \mathrm{H}_{58}$ & 394 & 111 & 200 \\
\hline Sterane & $\mathrm{C}_{27} \mathrm{H}_{46}$ & 370 & n.d. & 202 \\
\hline Methyl pentacosanoate & $\mathrm{C}_{26} \mathrm{H}_{52} \mathrm{O}_{2}$ & 396 & 114 & n.d. \\
\hline Perylene & $\mathrm{C}_{20} \mathrm{H}_{12}$ & 252 & n.d. & 204 \\
\hline Cholestanone & $\mathrm{C}_{27} \mathrm{H}_{46} \mathrm{O}$ & 386 & n.d. & 206 \\
\hline Nonacosane & $\mathrm{C}_{29} \mathrm{H}_{60}$ & 408 & 116 & 208 \\
\hline Sterane & $\mathrm{C}_{28} \mathrm{H}_{48}$ & 384 & n.d. & 210 \\
\hline Methyl cerotate & $\mathrm{C}_{27} \mathrm{H}_{54} \mathrm{O}_{2}$ & 410 & 120 & 211 \\
\hline Sterane & $\mathrm{C}_{29} \mathrm{H}_{50}$ & 398 & n.d. & 219 \\
\hline Triacontane & $\mathrm{C}_{30} \mathrm{H}_{62}$ & 422 & 122 & 220 \\
\hline Sterone & $\mathrm{C}_{28} \mathrm{H}_{48} \mathrm{O}$ & 400 & n.d. & 223 \\
\hline
\end{tabular}




\begin{tabular}{|c|c|c|c|c|}
\hline \multirow[b]{3}{*}{ Compound Name } & & & \multicolumn{2}{|c|}{ Sample } \\
\hline & & & $\begin{array}{l}12-112-11-4 \\
10-99 \mathrm{~cm}\end{array}$ & $\begin{array}{l}12-114-5-5 \\
80-140 \mathrm{~cm}\end{array}$ \\
\hline & \multicolumn{2}{|c|}{$\begin{array}{l}\text { Composition and } \\
\text { Molecular Weight }\end{array}$} & $\begin{array}{l}\text { Spectrum Scan No. } \\
\text { (cf. Fig. 2a) }\end{array}$ & $\begin{array}{l}\text { Spectrum Scan No. } \\
\text { (cf. Fig. 4a) }\end{array}$ \\
\hline Triterpane & $\mathrm{C}_{30} \mathrm{H}_{50}$ & 420 & n.d. & 224 \\
\hline Methyl heptacosanoate & $\mathrm{C}_{28} \mathrm{H}_{56} \mathrm{O}_{2}$ & 424 & 126 & n.d. \\
\hline Hentriacontane & $\mathrm{C}_{31} \mathrm{H}_{64}$ & 436 & 130 & 230 \\
\hline Triterpane & $\mathrm{C}_{30} \mathrm{H}_{52}$ & 412 & 132 & 231 \\
\hline Triterpane & $\mathrm{C}_{31} \mathrm{H}_{52}$ & 424 & n.d. & 234 \\
\hline Methyl octacosanoate & $\mathrm{C}_{29} \mathrm{H}_{58} \mathrm{O}_{2}$ & 438 & 134 & n.d. \\
\hline Dotriacontane & $\mathrm{C}_{32} \mathrm{H}_{66}$ & 450 & 138 & n.d. \\
\hline Triterpane & $\mathrm{C}_{32} \mathrm{H}_{54}$ & 438 & 144 & 250 \\
\hline Tritriacontane & $\mathrm{C}_{33} \mathrm{H}_{68}$ & 464 & 148 & n.d. \\
\hline Methyl triacontanoate & $\mathrm{C}_{31} \mathrm{H}_{62} \mathrm{O}_{2}$ & 466 & 156 & n.d. \\
\hline Pentatriacontane & $\mathrm{C}_{35} \mathrm{H}_{72}$ & 492 & 176 & n.d. \\
\hline $\begin{array}{l}m \text { - or } p \text {-( } 4,8,12 \text {-trimethyl- } \\
\text { tridecyl- } 1,5,9,13 \text {-tetra- } \\
\text { methyltetradecyl)benzene }\end{array}$ & $\mathrm{C}_{40} \mathrm{H}_{74}$ & 554 & n.d. & 275 \\
\hline
\end{tabular}

\footnotetext{
$a_{\text {n.d. }}=$ not detected
}

${ }^{b}$ The configurations of the alkanes and acids ( $n-$, iso-, or anteiso-) are not specified, but they are probably predominantly normal.

cProbably sample vial cap contamination.

dProbably core tube contamination.

compound is underway to allow correlation of the mass spectrometric data. Contaminants from core tube material and phthalate esters were not detected in this fraction.

The benzene and methanol soluble fraction contains mainly contaminants and traces of alkanes (cf. Figure $5 \mathrm{~b}$ ). The major peak in the GC trace (Figure 4b) is due to dioctyl 2,3-dimethylsuccinate (Structure IX), which exhibits a base peak at m/e 129 (Structure X-cf. Figure 5c). Its mass spectrum is shown in Figure $5 \mathrm{e}$ and the major fragment ions are indicated in the following scheme:

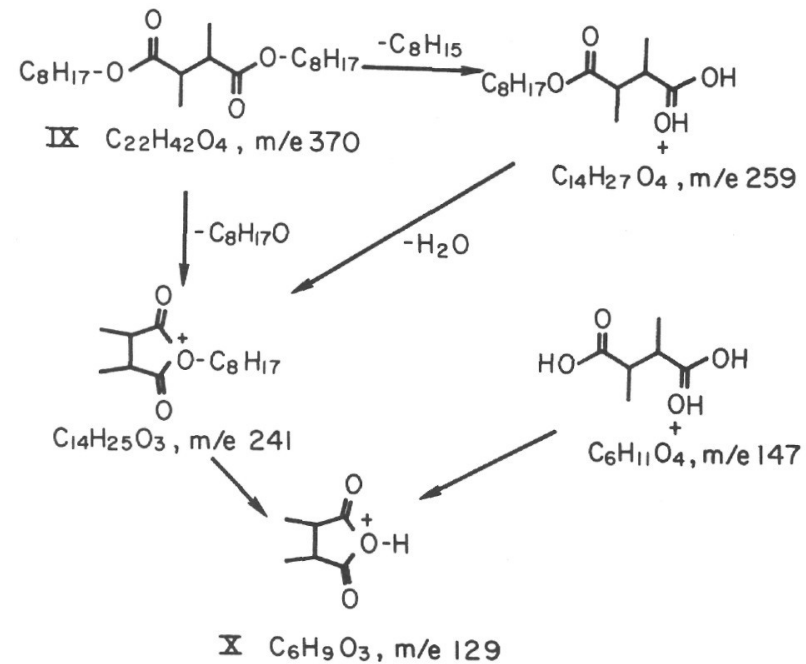

Various isomers of dioctyl phthalate are indicated by the triplet of the base peak m/e 149 (Figure 5d) in the scan region 231 to 239 .

\section{Site 128}

The extracts of the sample $(13-128-3-4,122-124 \mathrm{~cm})$ from the 84.8 -meter level below the seabed were analyzed by $\mathrm{GC}$, high resolution mass spectrometry, and GC/MS. The GC traces are shown in Figure 6, and selected high resolution mass spectrometric (HRMS) $\mathrm{data}^{2}$ for the two

\footnotetext{
${ }^{2}$ In this report, all high resolution mass spectra are presented as heteroatomic plots (Burlingame and Smith, 1968) with the masses plotted in methylene units. On the abscissa, each principal division marker corresponds to the saturated alkyl fragment (evenelectron ion), for example, $\mathrm{C}_{n} \mathrm{H}_{2 n+1}$, with the number of carbon and hydrogen atoms given subsequently. Each principal division of the abscissa is further divided into seven units. The number of hydrogen atoms of an unsaturated or cyclic-fragment ion is obtained by subtracting the number of units (two hydrogen atoms) or half units from the $2 n+1$ hydrogen atoms of the respective saturated principal division, $\mathrm{C}_{n} \mathrm{H}_{2 n+1}$. Fragments which have more than seven degrees of unsaturation are plotted as heteroatomic plots where each principal division marker on the abscissa corresponds to the fragment ion $\mathrm{C}_{n} \mathrm{H}_{2 n-13}$. Each principal division is again further divided into seven units and the number of hydrogen atoms of a fragment ion is derived as discussed above. The origin of the abscissas is the same $\mathrm{m} / \mathrm{e}$ ratio for each plot, thus the nominal masses from plot to plot lie directly above one another and a superposition of the plots yields a "low" resolution mass spectrum of the sample (presented at the bottom of each figure). The nominal masses are indicated in 50 mass unit intervals below the carbon/hydrogen ratio scale. All plots are normalized to a base peak (usually the base peak of the entire spectrum, unless otherwise specified) on the relative intensity scale. In order to make high mass, low intensity features of the spectrum observable, the whole spectrum or any region thereof can be multiplied by a scale factor. This factor is indicated by $/ \times 00$ at the point of scale expansion.
} 
total extract fractions are shown in Figures 7 and 8 . The salient features of the GC/MS analysis of the heptane-ether soluble fraction appear in Figures 9 and 10 and are summarized in Table 4. The major constituents of the heptane/ether soluble fraction, as discerned by the HRMS data (Figure 7), are hydrocarbons of the series, $\mathrm{C}_{n} \mathrm{H}_{2 n+2}$ to $\mathrm{C}_{n} \mathrm{H}_{2 n-18}$, ranging from $n=3-32$; however, not every homolog of each series has been detected. The peaks of compositions $\mathrm{C}_{14} \mathrm{H}_{23}$ at $\mathrm{m} / \mathrm{e} 191$ (Structure I) and $\mathrm{C}_{16} \mathrm{H}_{25}$ at $\mathrm{m} / \mathrm{e} 217$ (Structure $\mathrm{XI}$ ) are above background

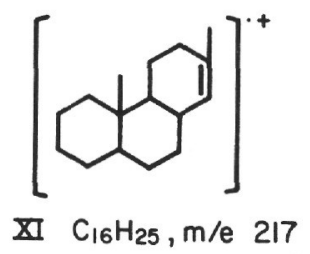

levels. Oxygenated steroidal species (cf. $\mathrm{C} / \mathrm{H} \mathrm{O} 2$ and $\mathrm{C} / \mathrm{H} \mathrm{O}$ plots of Figure 7), which are not resolved in the GC/MS data, are present: $\mathrm{C}_{n} \mathrm{H}_{2 n-8} \mathrm{O}_{2}$, for $n=28$ and 29; $\mathrm{C}_{n} \mathrm{H}_{2 n-10} \mathrm{O}_{2}$, for $n=27-29$; and minor amounts of $\mathrm{C}_{n} \mathrm{H}_{2 n-8} \mathrm{O}, \mathrm{C}_{n} \mathrm{H}_{2 n-10} \mathrm{O}$ and $\mathrm{C}_{n} \mathrm{H}_{2 n-12} \mathrm{O}$, all for $n=$ 27-29. The sterane series $\mathrm{C}_{n} \mathrm{H}_{2 n-8}$ and $\mathrm{C}_{n} \mathrm{H}_{2 n-10}$, both for $n=27-29$, were also detected. The peak of composition $\mathrm{C}_{19} \mathrm{H}_{27} \mathrm{O}$ (cf. $\mathrm{C} / \mathrm{H} \mathrm{O}$ plot of Figure 7) can be assigned possible Structure XII, the fragment ion of a triterpenone corresponding to the $\mathrm{m} / \mathrm{e} 191$ fragment in the case of a triterpane. The additional degree of unsaturation indicates a double bond in the parent molecule, which has the composition $\mathrm{C}_{30} \mathrm{H}_{48} \mathrm{O}$ (cf. $\mathrm{C} / \mathrm{H} 0$ plot of Figure 7 ). The peak due to loss of a methyl radical from the molecular ion was also detected. The probable structure of this triterpenone is XIII, derived by mild diagenetic oxidation

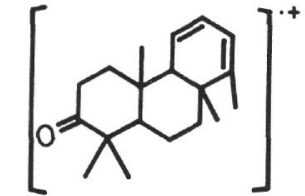

XII $\mathrm{C}_{19} \mathrm{H}_{27} \mathrm{O}, \mathrm{m} / \mathrm{e} 27 \mathrm{I}$

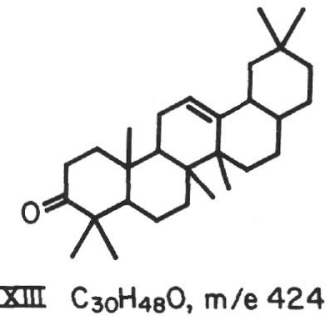

of an amyrin. The carboxylic acids, $\mathrm{C}_{n} \mathrm{H}_{2}{ }_{n} \mathrm{O}_{2}$, were found (as methyl esters) from $n=3-20$. Contaminants from the core tube (dibutyl esters) or phthalate esters were not detected in these data.

The major homologous series detected in the GC/MS data (cf. Figures 9 and 10 and Table 4) are normal alkanes (cf. Figure 9b), $\mathrm{C}_{n} \mathrm{H}_{2 n+2}$, for $n=16-33$, with an odd/even predominance. Carboxylic acids (as the methyl esters Simoneit et al., 1973a) were also abundant; the series $\mathrm{C}_{n} \mathrm{H}_{2 n} \mathrm{O}_{2}$ (cf. Figure 9c) ranged from $n=15-28$, with an even/odd predominance. Steranes (mainly $\mathrm{C}_{2}{ }_{9} \mathrm{H}_{52}$ and $\mathrm{C}_{30} \mathrm{H}_{54}$ ) and triterpanes (mainly $\mathrm{C}_{30} \mathrm{H}_{52}$ ) were detected as minor constituents in the mixture. Minor amounts of phthalate esters and core tube contaminants were detected in the GC/MS data. The major peak in the GC trace of this extract (cf. Figure 6a), as well as in the benzene/methanol soluble fraction (cf. Figure $6 \mathrm{~b}$ ), is the isoprenoidal ketone 6,10,14-trimethylepentadecan-2-one (Structure VI). The mass spectrum (cf. Figure 10b) matches that of the synthetic standard compound derived from the oxidation of phytol (Cox, 1971). The molecule fragments (cf. Structure XIV) by loss of $\mathrm{H}_{2} \mathrm{O}$ from the molecular ion $(\mathrm{m} / \mathrm{e}$

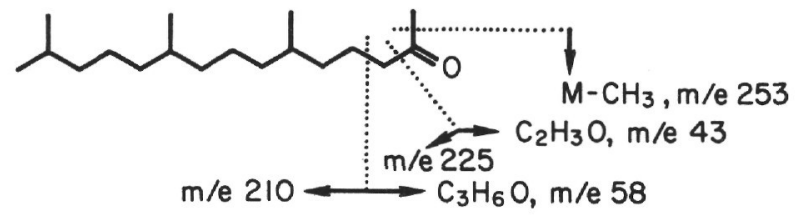

XIV $\mathrm{C}_{18} \mathrm{H}_{36} \mathrm{O}, \mathrm{m} / \mathrm{e} 268$

268 ) to yield the even mass ion at $\mathrm{m} / \mathrm{e} 250$, and by loss of both $\mathrm{C}_{2} \mathrm{H}_{3} \mathrm{O}(\mathrm{m} / \mathrm{e} 43)$ and $\mathrm{C}_{3} \mathrm{H}_{6} \mathrm{O}(\mathrm{m} / \mathrm{e} 58)$ from the molecular ion to yield the peaks at $\mathrm{m} / \mathrm{e} 225$ and 210 , respectively. The two major peaks of the spectrum are $\mathrm{m} / \mathrm{e}$ 43 and 58 (cf. Figure 10a). A lower homolog of this ketone is also present in this sample (cf. Figure 10a, scan 93). This compound is 6,10-dimethylundecan-2-one (Structure XV). The scan 115 spectrum (cf. Figure 10a) is predominantly heneicosane and not another ketone.

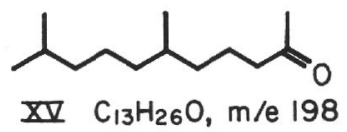

The major constituents of the benzene/methanol soluble fraction determined by the HRMS data (cf. Figure 8) are hydrocarbons of the series, $\mathrm{C}_{n} \mathrm{H}_{2 n+2}$ to $\mathrm{C}_{n} \mathrm{H}_{2 n-18}$, ranging from $n=3-22$; however, each homolog of every series was not detected. The peak of composition $\mathrm{C}_{14} \mathrm{H}_{23}$ at $\mathrm{m} / \mathrm{e} 191$ (Structure I) is above background. The peaks of compositions $\mathrm{C}_{16} \mathrm{H}_{25}$ at $\mathrm{m} / \mathrm{e} 217$ (Structure XI) and $\mathrm{C}_{16} \mathrm{H}_{23} \mathrm{O}$ at $\mathrm{m} / \mathrm{e} 231$ (Structure IV) are slightly above background levels and corroborate the presence of steroidal compounds. The series $\mathrm{C}_{n} \mathrm{H}_{2 n-8} \mathrm{O}$ and $\mathrm{C}_{n} \mathrm{H}_{2 n-10} \mathrm{O}$ are present for $n=27-29$ (cf. C/H O plot of Figure 8 ) and in the $\mathrm{C} / \mathrm{H} \mathrm{O} \mathrm{O}_{2}$ data the molecular ions $\mathrm{C}_{29} \mathrm{H}_{50} \mathrm{O}_{2}$ and $\mathrm{C}_{29} \mathrm{H}_{48} \mathrm{O}_{2}$ are present. The molecular ions of the steranes $\mathrm{C}_{27} \mathrm{H}_{44}, \mathrm{C}_{27} \mathrm{H}_{46}$, and $\mathrm{C}_{28} \mathrm{H}_{44}$ were also detectable. The fragment ions $\mathrm{C}_{19} \mathrm{H}_{27}$ and $\mathrm{C}_{19} \mathrm{H}_{27} \mathrm{O}$ (Structure XII) were also intense in these data, indicating the presence of the triterpenoidal compound $\mathrm{C}_{30} \mathrm{H}_{48} \mathrm{O}$ (Structure XIII).

The extracts of the sample $(13-128-3-5,38-40 \mathrm{~cm})$ from the 85.4-meter level below the seabed were analyzed by GC and HRMS. The GC traces are shown in Figure 11 and the HRMS data for the two extract fractions are shown in Figures 12-13. The GC traces for both fractions are virtually identical to the corresponding fractions from the 84.8-meter sample (cf. Figure 6). The major components identified in the HRMS data (Figure 12) of the heptane/ether fraction are hydrocarbons of the series, $\mathrm{C}_{n} \mathrm{H}_{2 n+2}$ to $\mathrm{C}_{n} \mathrm{H}_{2 n-16}$ for $n=3-33$, but not every homolog of each series was detected. The fragment peaks of compositions $\mathrm{C}_{14} \mathrm{H}_{23}$ at $\mathrm{m} / \mathrm{e} 191$ (Structure I), $\mathrm{C}_{16} \mathrm{H}_{25}$ at $\mathrm{m} / \mathrm{e} 233$ (Structure XI), $\mathrm{C}_{16} \mathrm{H}_{25} \mathrm{O}$ at m/e 233 (Structure $\mathrm{XVI}$ ), $\mathrm{C}_{16} \mathrm{H}_{23} \mathrm{O}$ at $\mathrm{m} / \mathrm{e} 231$ (Structure IV), $\mathrm{C}_{17} \mathrm{H}_{27} \mathrm{O}$ at $\mathrm{m} / \mathrm{e} 247$ Structure XVII), $\mathrm{C}_{19} \mathrm{H}_{27} \mathrm{O}$ at $\mathrm{m} / \mathrm{e} 271$ (Structure XII), and $\mathrm{C}_{19} \mathrm{H}_{29} \mathrm{O}$ at $\mathrm{m} / \mathrm{e} 273$ (Structure XVIII) are all above the background. Some of the molecular ions and/or the $\mathrm{M}-\mathrm{CH}_{3}$ species of the various homologous series 

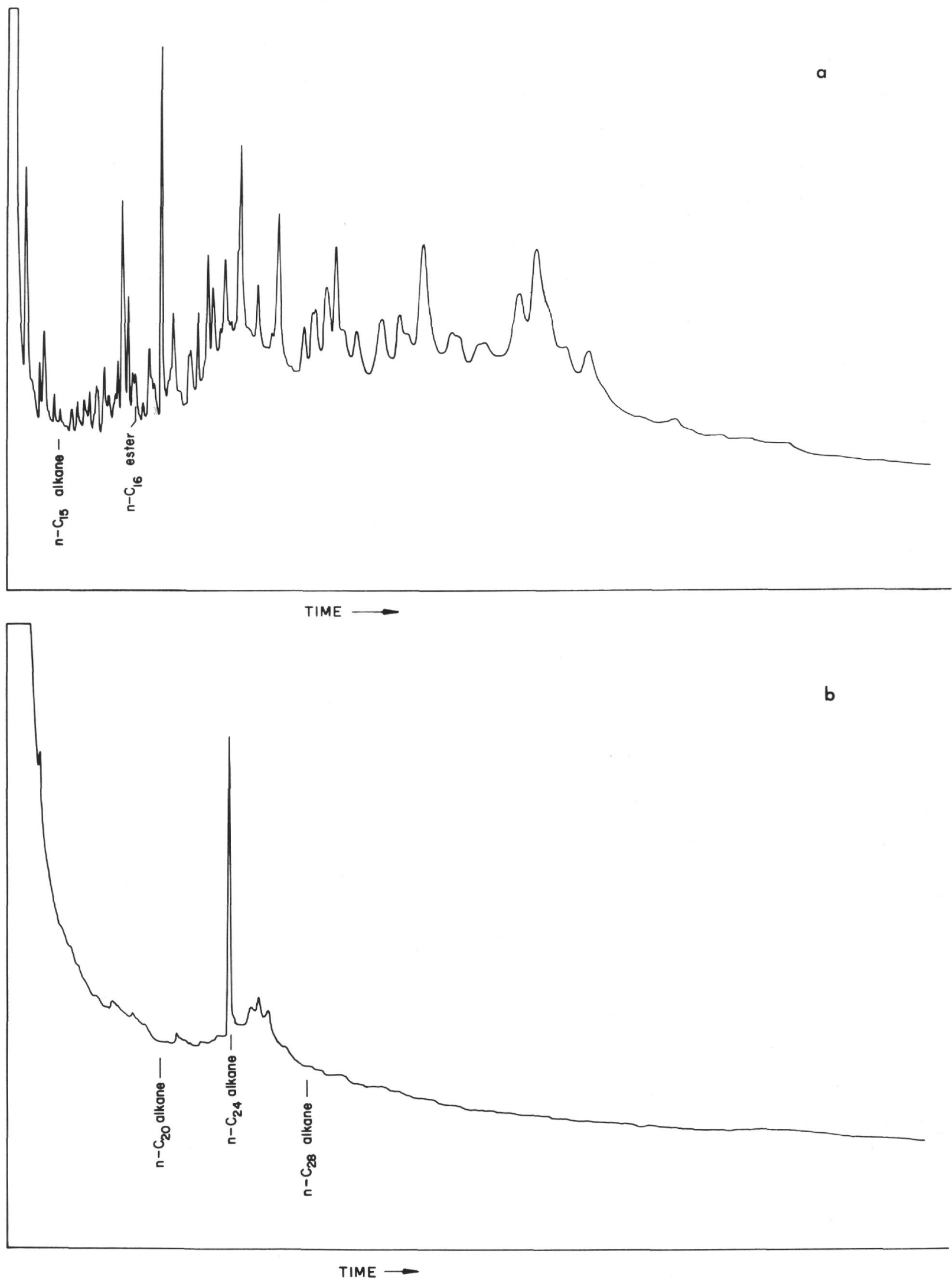

Figure 3. (a) GC trace of the heptane-ether soluble fraction from the exhaustive extract of Sample 12-114-5-5, 80-140 cm, (b) GC trace of the benzene and methanol soluble fraction from the exhaustive extract of Sample 12-114-5-5, 80-140 cm. (GC conditions as cited in Figure 1b.) 


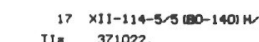

a

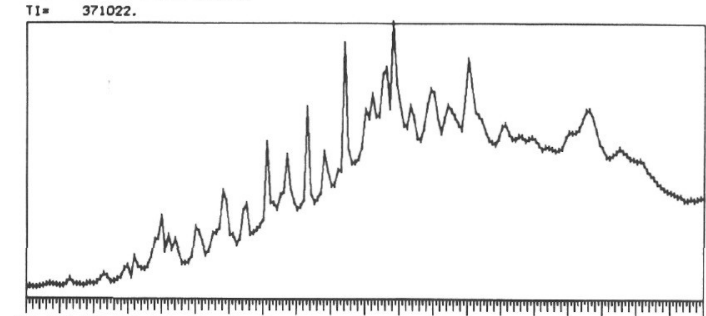

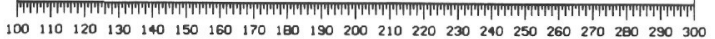

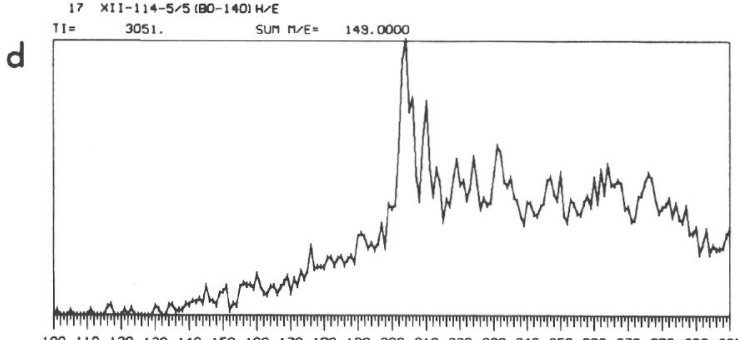

100110120130140150160170180190200210220230240250260270280290300

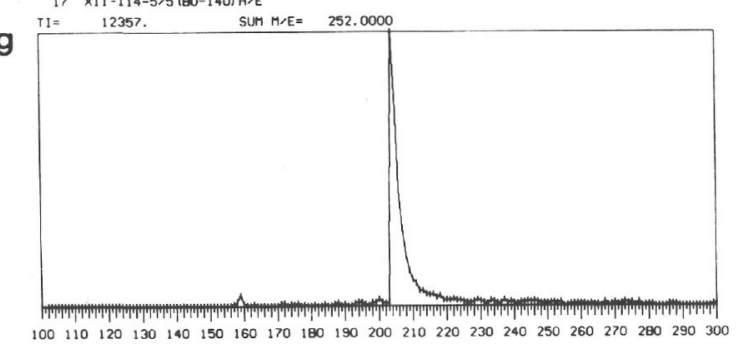

SCON $9001 \quad 17 \times 111-114-5,5(00-140) H / E$

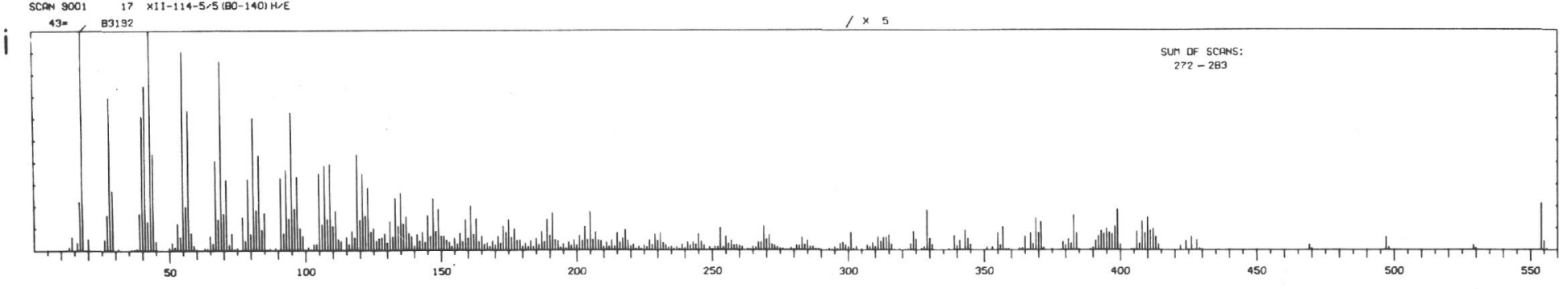

Figure 4. GC/MS data for the total heptane-ether soluble extract fraction from Sample 12-114-5-5, 80-140 cm (GC conditions as cited in Figure $1 \mathrm{~b}$ ). (a) total ionization sum plot, (b) m/e 57 sum plot, (c) m/e 74 sum plot, (d) m/e 149 sum plot, (e) m/e 191 sum plot, (f) m/e 231 sum plot, (g) m/e 252 sum plot, (h) m/e 554 sum plot, (i) m/e 115 sum plot, (j) summed mass spectrum scans 272 to 283 [mixture, mainly m- or p-14,8,12-trimethyltridecyl-1,5,9,13-tetramethyltetradecyl)benzene, MW 554 and various triterpanes, $M W$ 406-414 and 422-428].
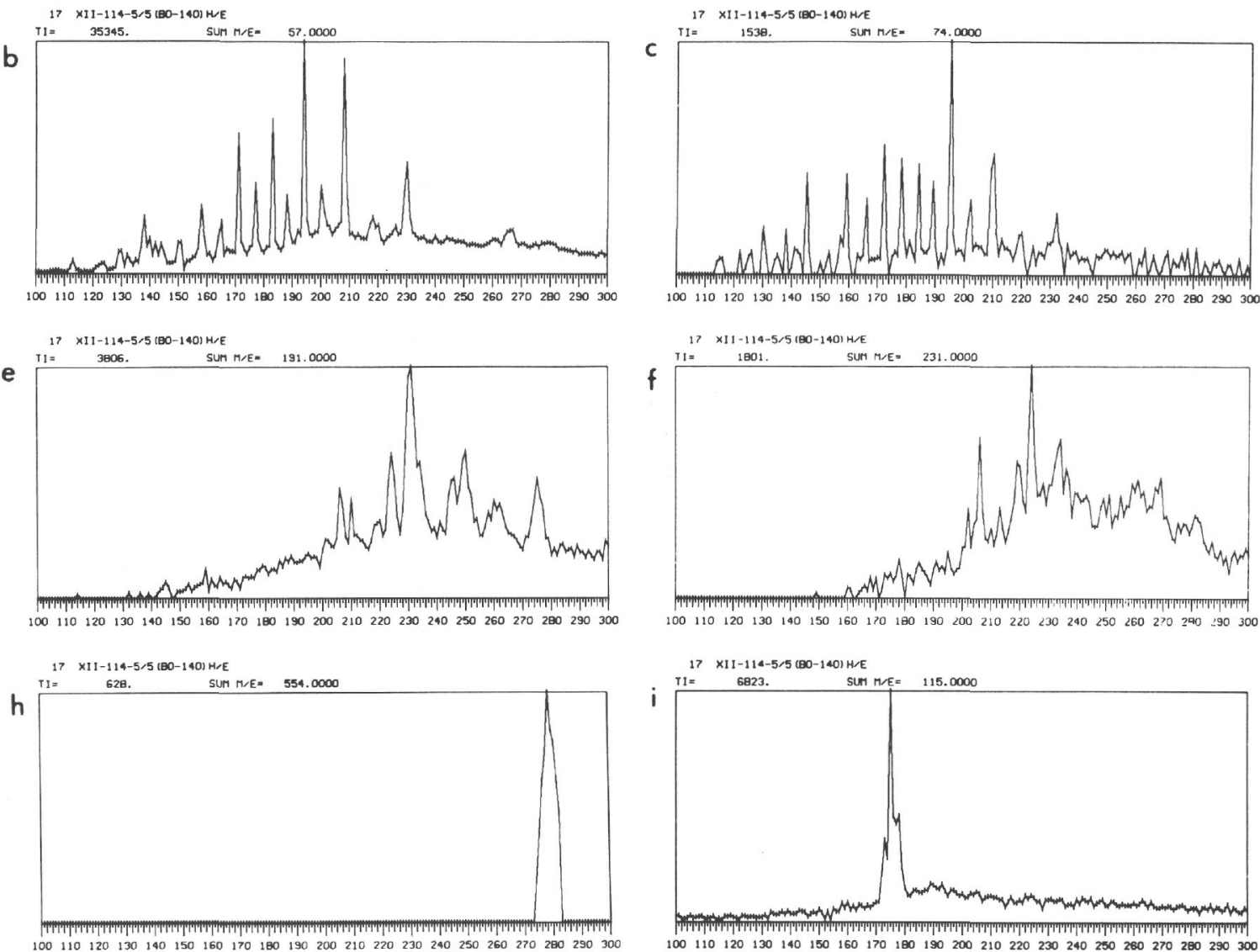
6 XI1-114-5/5 (BO-140) $0 E$-TE

$T=$

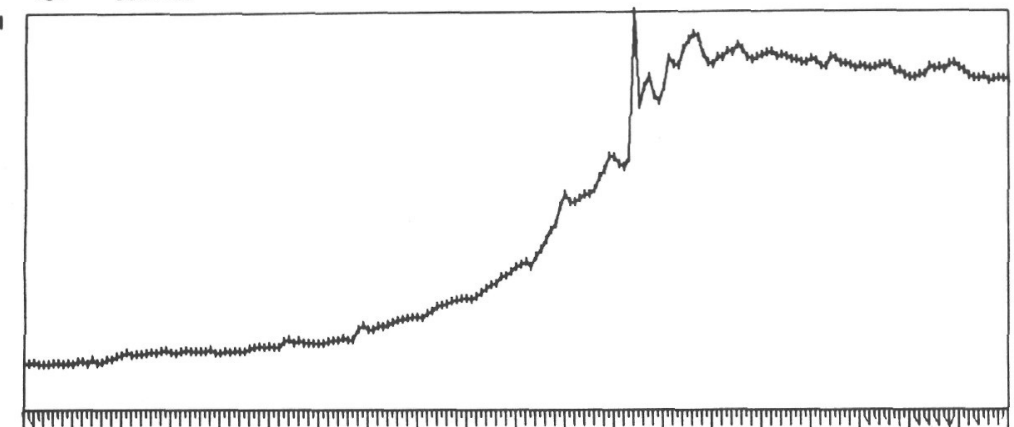

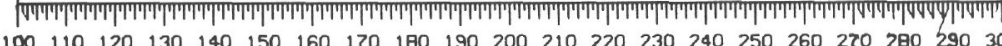
$100110120130140150160170180190200210220230240250260 \quad 270 \quad 280290300$
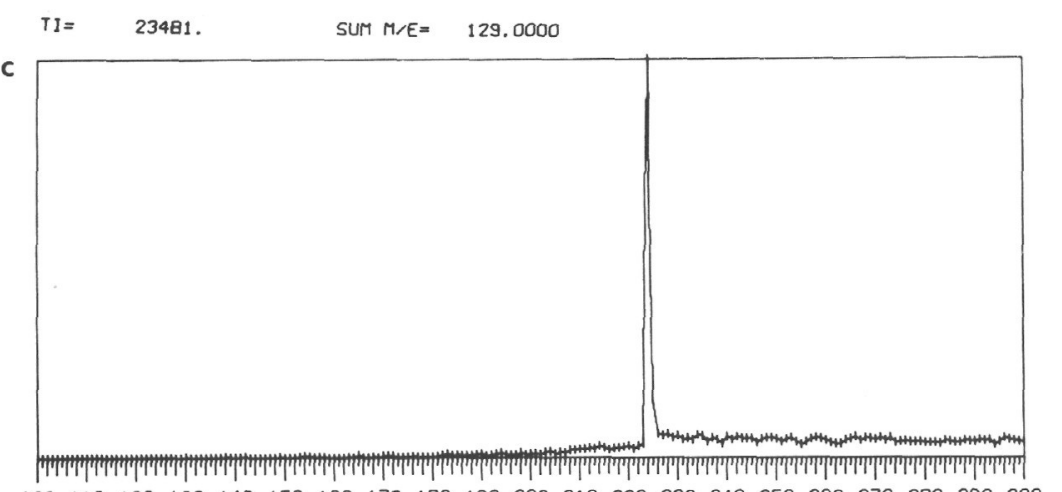

$100 \quad 110 \quad 120 \quad 130 \quad 140 \quad 150160 \quad 170 \quad 180 \quad 190200210220230240250260270280290300$

$$
\times^{224} 5>210 \quad 129=23481
$$

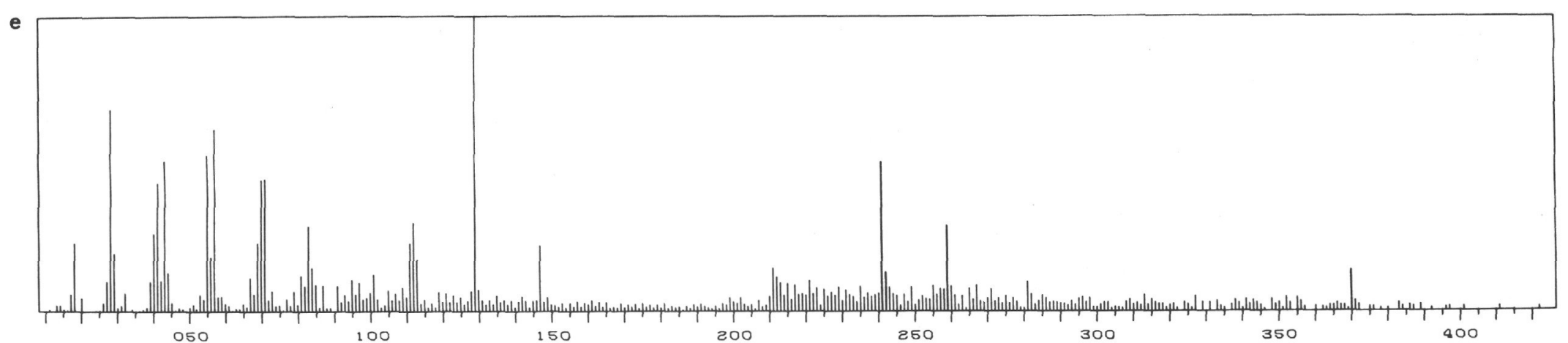

Figure 5. GC/MS data for the total benzene/methanol soluble extract fraction from Sample 12-114-5-5, 80-140 cm (GC conditions as cited in Figure 1b). (a) total ionization sum plot, (b) m/e 57 sum plot, (c) m/e 129 sum plot, (d) m/e 149 sum plot, (e) mass spectrum scan 224 (dioctyl 2,3-dimethylsuccinate, MW 370).

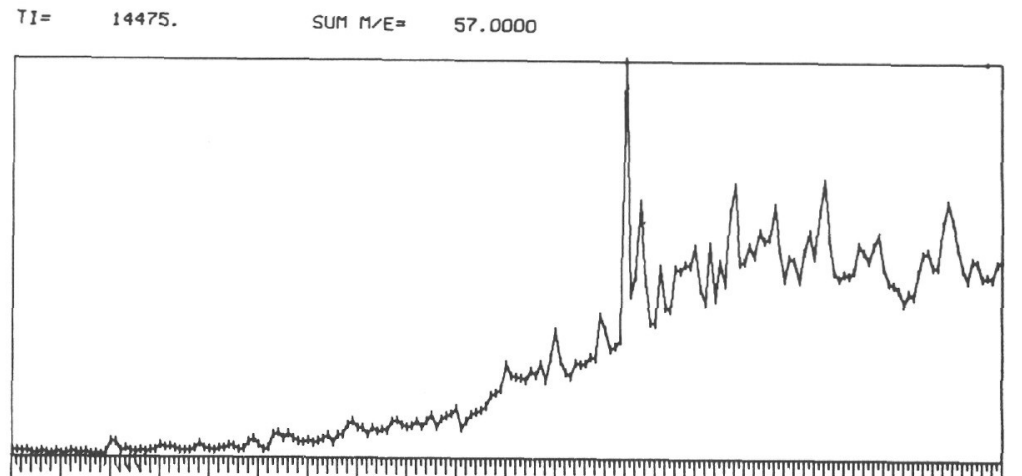

$100 \quad 110120130140150160170180190200210220 \quad 230 \quad 240 \quad 250260 \quad 270 \quad 280290300$

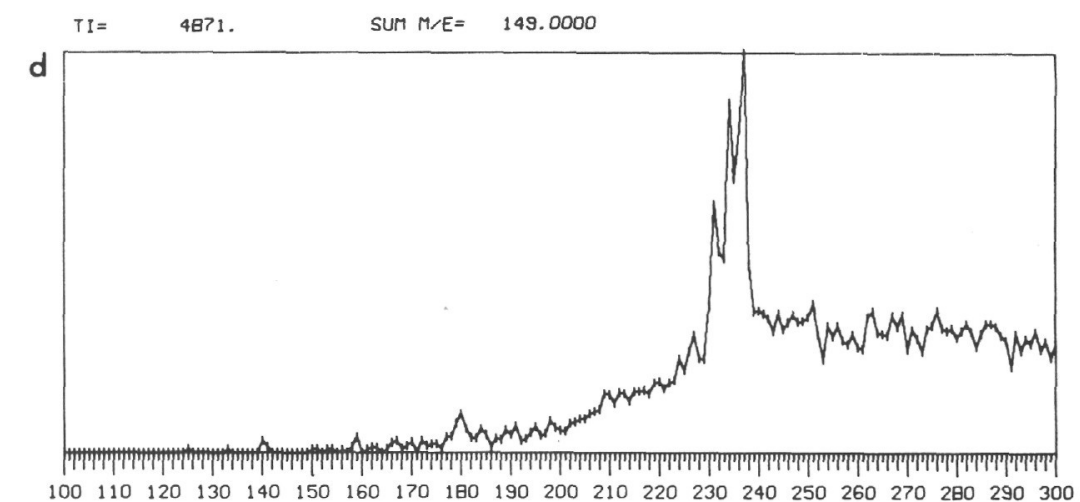




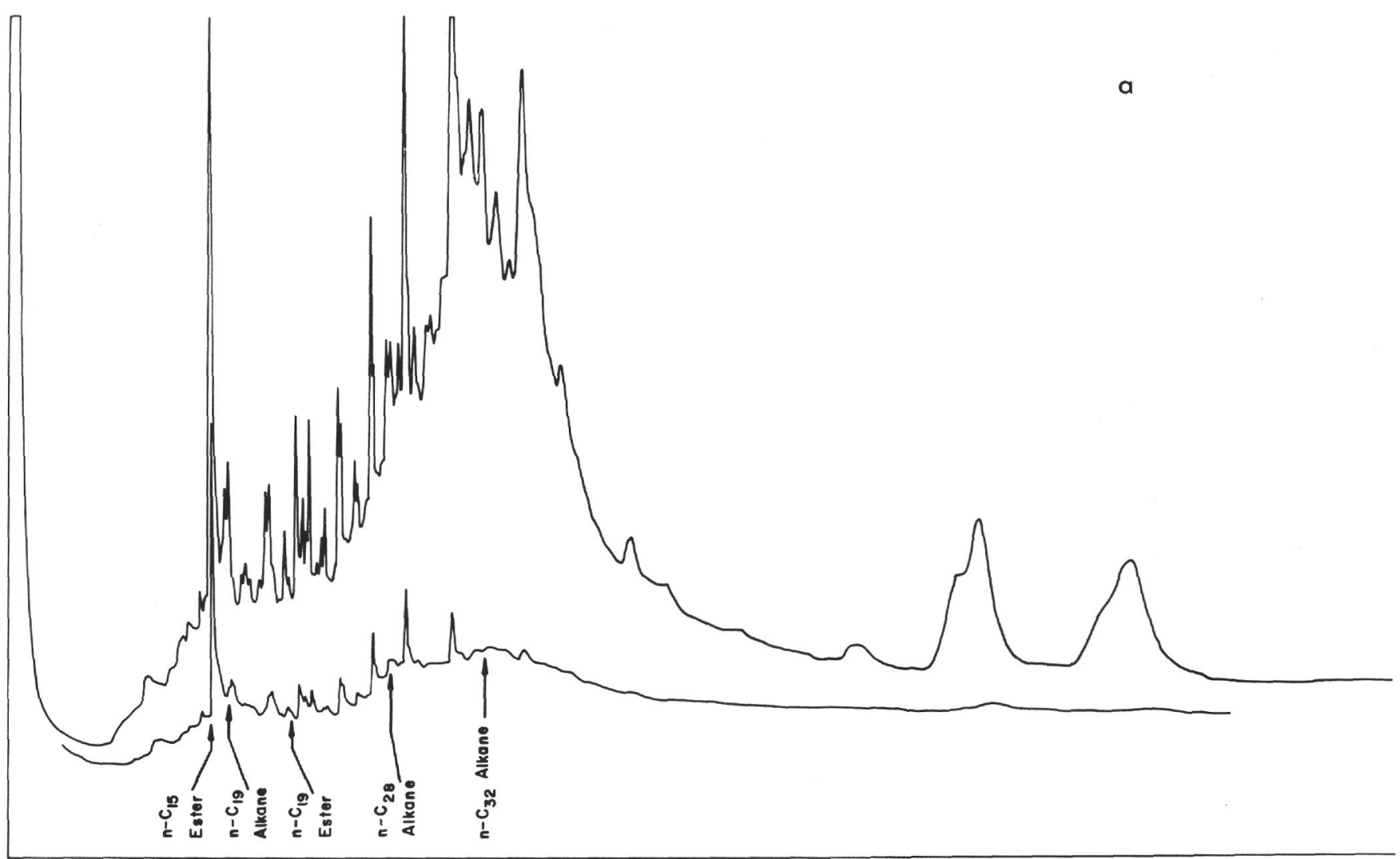

TIME

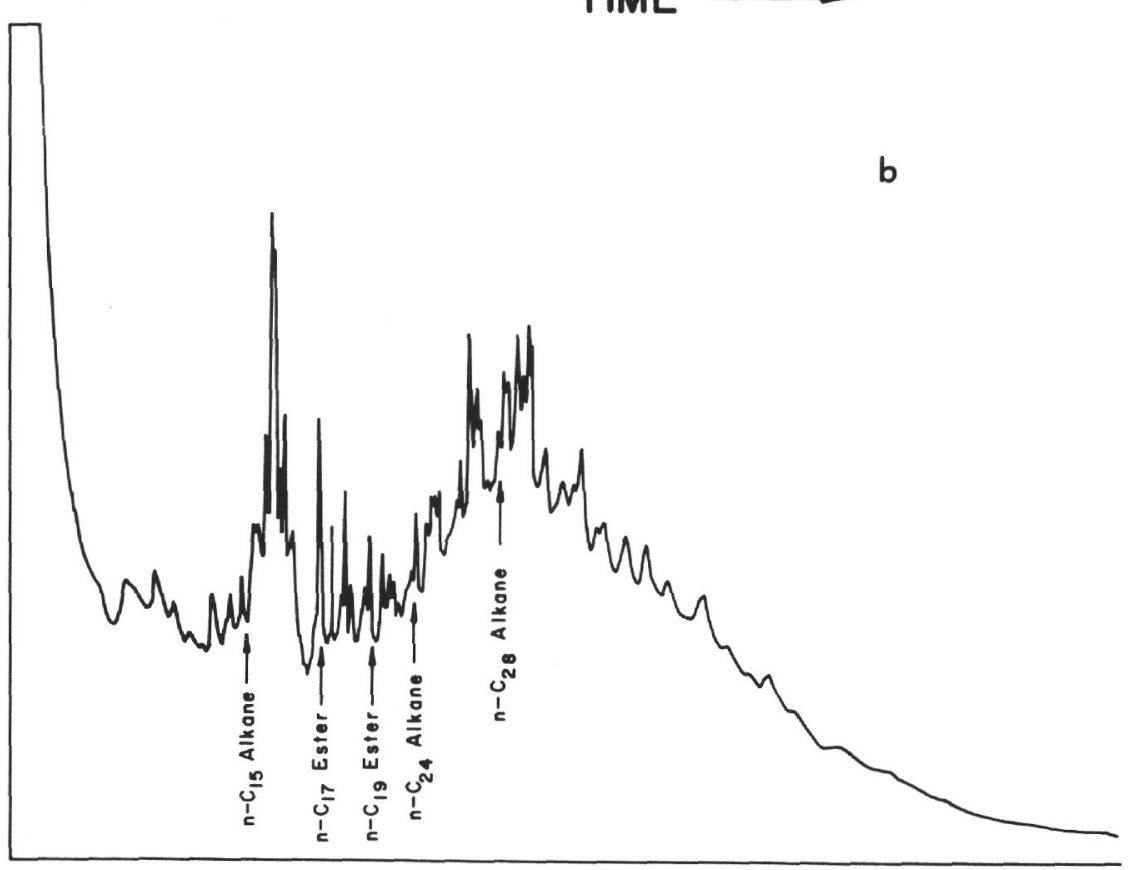

TIME

Figure 6. (a) GC trace of the heptane soluble fraction from the exhaustive extract of Sample 13-128-3-4, 122-124 cm, (b) GC trace of the benzene and methanol soluble fraction from the exhaustive extract of Sample 13-128-3-4, 122-124 cm. /GC conditions: $7.5 \mathrm{ft} \times 1 / 8 \mathrm{in}$. stainless steel column packed with 3\% OV-1 on 100-200 mesh Gaschrom Q, programmed from 100 to $275^{\circ} \mathrm{C}$ at $8^{\circ} / \mathrm{min}$ and using He carrier gas at $50 \mathrm{ml} / \mathrm{min}$ ) 

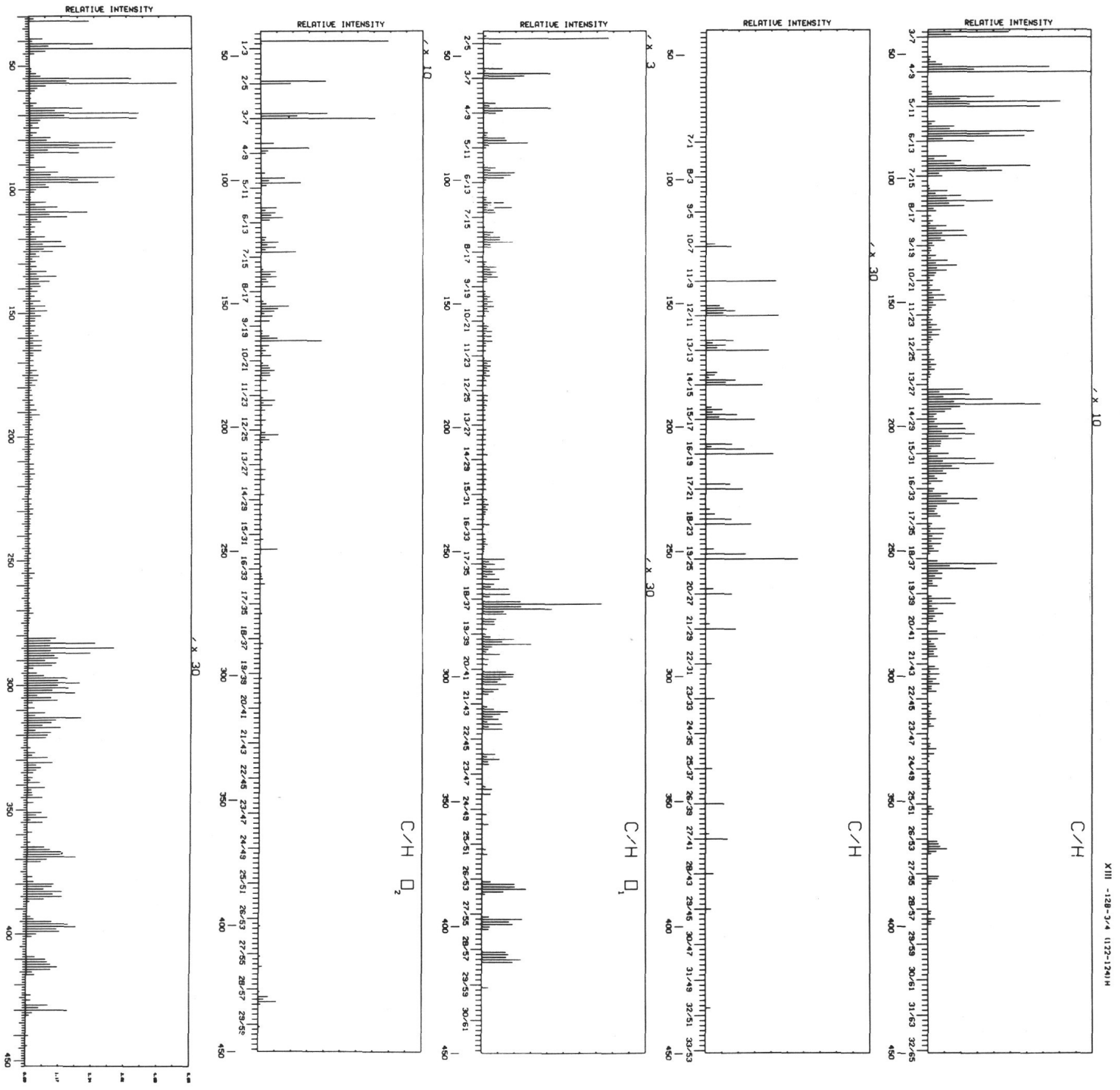

Figure 7. Partial high resolution mass spectrometric data for the heptane soluble fraction from the exhaustive extract of Sample 13-128-3-4, 122-124 cm. 

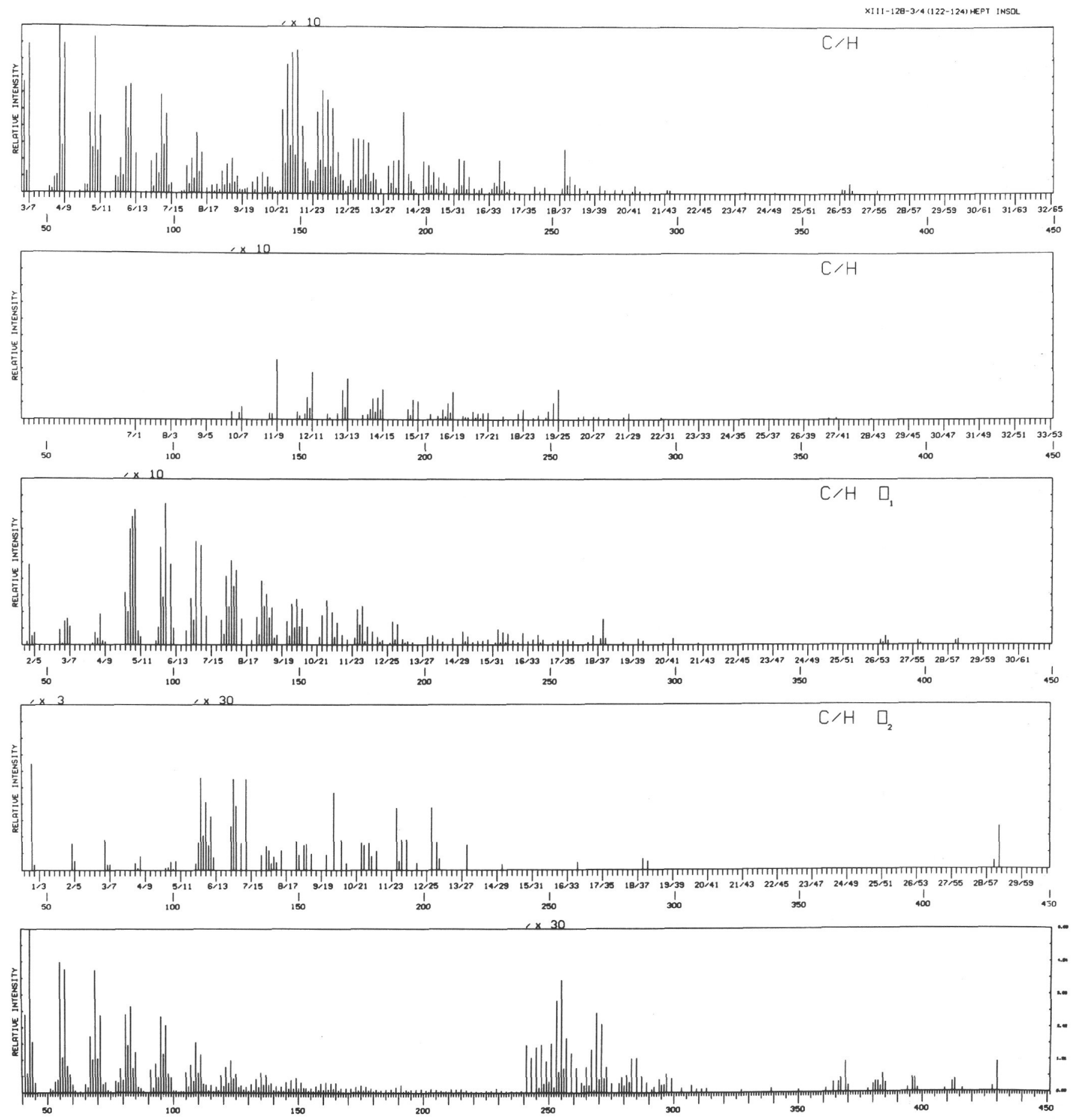

Figure 8. Partial high resolution mass spectrometric data for the benzene and methanol soluble fraction from the exhaustive extract of Sample 12-128-3-4, 122-124 cm. 
$21 \times 111-128-3 / 4(122-124) \mathrm{H}$

$\mathrm{TI}=50 \mathrm{~B} 733$.
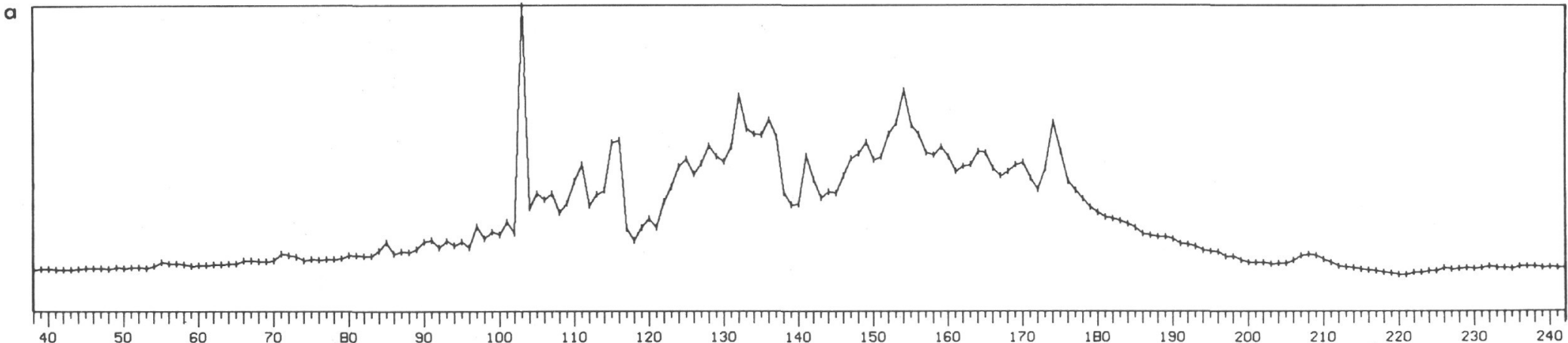

$21 \times 111-128-3 / 4(122-124) H$

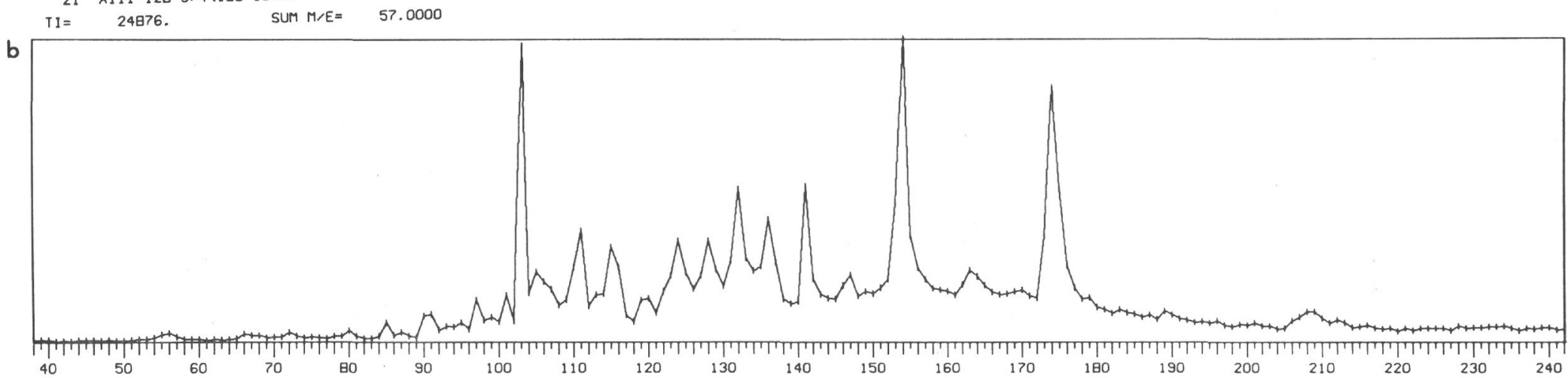

$21 \times 111-128-3 / 4(122-124) \mathrm{H}$

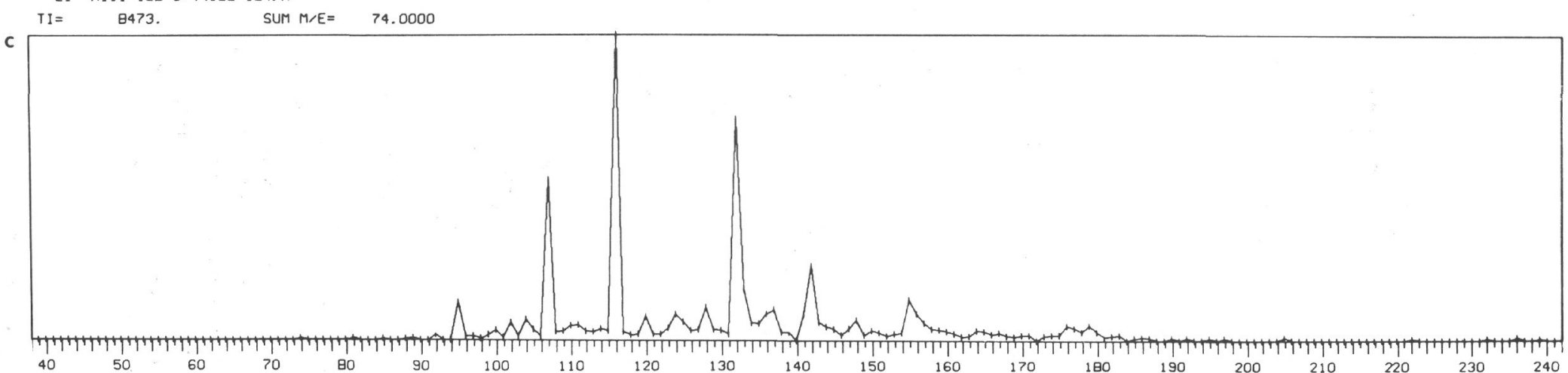

Figure 9. GC/MS data for the total heptane-ether soluble extract fraction from Sample 13-128-3-4, $122-124 \mathrm{~cm}$ (GC conditions as cited in Figure 6b).

(a) total ionization sum plot, (b) m/e 57 sum plot, (c) m/e 74 sum plot. 


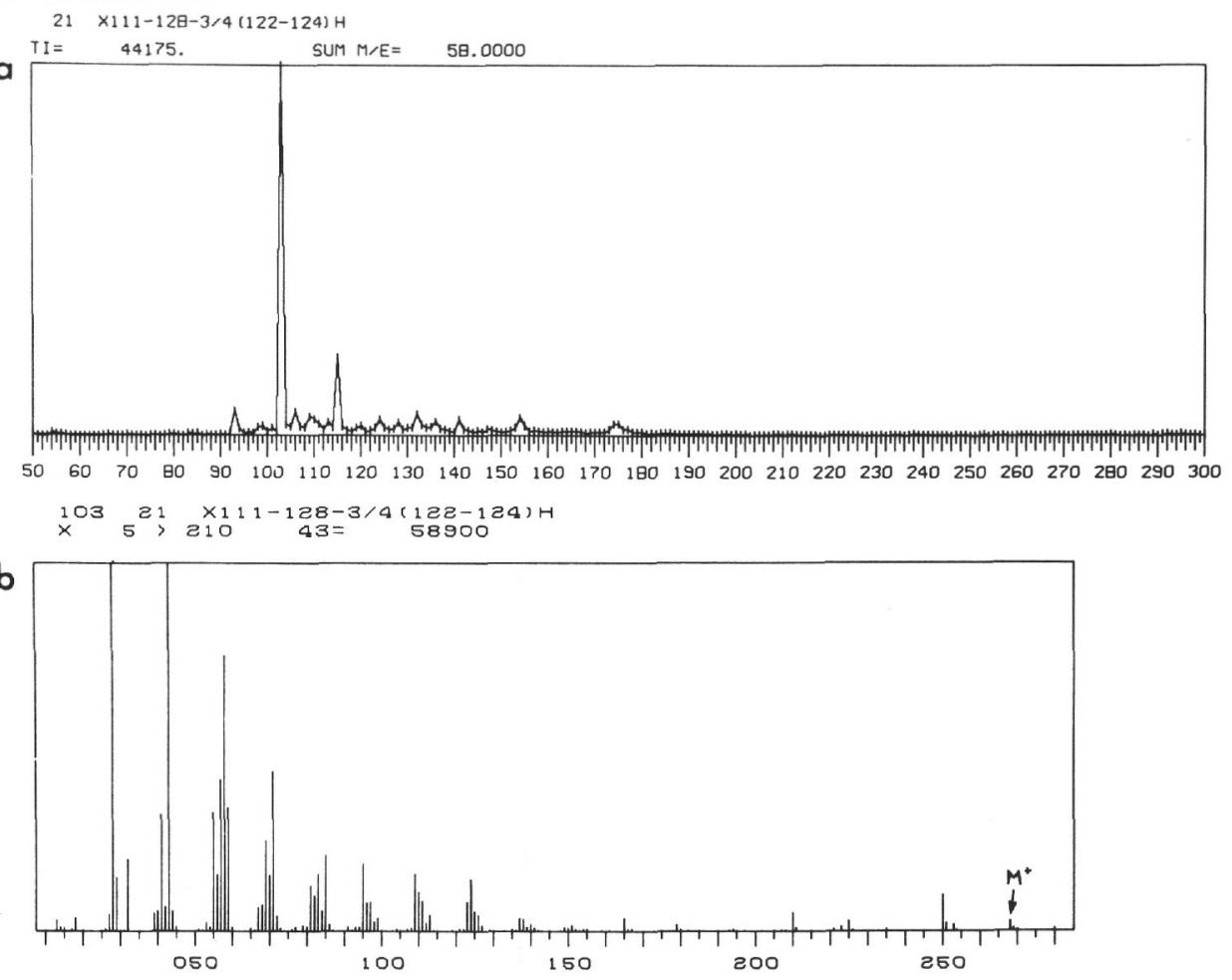

Figure 10. GC/MS data for the total heptane-ether soluble extract fraction from Sample 13-128-3-4, 122-124 cm (GC conditions as cited in Figure 6b). (a) m/e 58 sum plot, (b) mass spectrum scan 103 (6,10,14-trimethylpentadecan-2-one, MW 268).
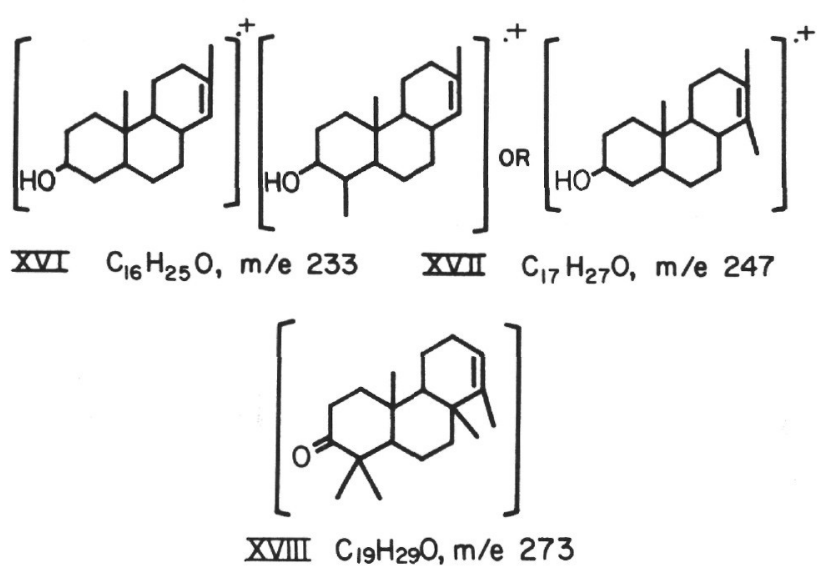

indicated by these fragment ions appear in the $\mathrm{C} / \mathrm{H} \mathrm{O}, \mathrm{C} / \mathrm{H}$ $\mathrm{O}_{2}$, and $\mathrm{C} / \mathrm{H} \mathrm{O}_{3}$ data in Figure 12. The steroidal compounds are $\mathrm{C}_{n} \mathrm{H}_{2 n-6} \mathrm{O}, \mathrm{C}_{n} \mathrm{H}_{2 n-8} \mathrm{O}$, and $\mathrm{C}_{n} \mathrm{H}_{2 n-10} \mathrm{O}$, ranging from $n=27-29 ; \mathrm{C}_{n} \mathrm{H}_{2 n-8} \mathrm{O}_{2}$ and $\mathrm{C}_{n} \mathrm{H}_{2 n-10} \mathrm{O}_{2}$, for mainly $n=29$; and $\mathrm{C}_{n} \mathrm{H}_{2 n-10}$, ranging from $n=25-30$ and maximizing at $n=29$. The major steroidal compound series in this mixture are the stanols, mainly cholestanol and stigmastanol. The triterpanoidal compounds are mainly $\mathrm{C}_{30} \mathrm{H}_{50} \mathrm{O}$ (possible Structure XIX), $\mathrm{C}_{30} \mathrm{H}_{48} \mathrm{O}_{2}$ (possible Structure XX), $\mathrm{C}_{30} \mathrm{H}_{50} \mathrm{O}_{2}$, and $\mathrm{C}_{30} \mathrm{H}_{52} \mathrm{O}_{2}$. Carboxylic

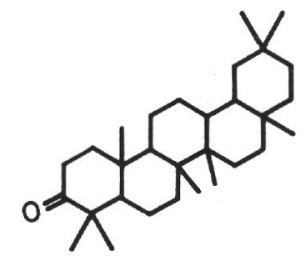

XIX $\mathrm{C}_{30} \mathrm{H}_{50} \mathrm{O}, \mathrm{m} / \mathrm{e} 426$

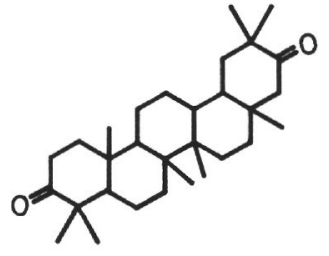

XX $\mathrm{C}_{30} \mathrm{H}_{48} \mathrm{O}_{2}, \mathrm{~m} / \mathrm{e} 440$ acids (probably as the methyl esters - Simoneit et al., in press), $\mathrm{C}_{n} \mathrm{H}_{2 n} \mathrm{O}_{2}$, were found from $n=3-28$. Contaminants from core tube material as dibutyl esters and from phthalate esters (cf. peak of composition $\mathrm{C}_{8} \mathrm{H}_{5} \mathrm{O}_{3}$ at m/e 149 in $\mathrm{C} / \mathrm{H} \mathrm{O}_{3}$ plot of Figure 12) are minor.

The HRMS data for the benzene/methanol soluble fraction (Figure 13) indicate mainly hydrocarbons of the series, $\mathrm{C}_{n} \mathrm{H}_{2 n+2}$ to $\mathrm{C}_{n} \mathrm{H}_{2 n-16}$, ranging from $n=3-25$, but not each homolog was detected. Minor amounts of stanols and carboxylic acids (as methyl esters) were also indicated, and no contaminants from core tube material and phthalate esters were found.

\section{Site 130}

The GC traces for the extract fractions from Sample 13-130-1-2, 123-125 cm are shown in Figure 14. These fractions were analyzed by HRMS and GC/MS. Selected HRMS data for the two total fractions are shown in Figures 15 and 16. The salient features of the GC/MS analysis of the heptane/ether soluble fraction appear in Figure 17, and the results are listed in Table 4. The major component series in the HRMS data (Figure 15) are hydrocarbons, $\mathrm{C}_{n} \mathrm{H}_{2 n+2}$ to $\mathrm{C}_{n} \mathrm{H}_{2 n-16}$, ranging from $n=3-35$ (not each homolog was detected), and steroidal and triterpenoidal compounds. The molecular ions of the following steroidal compositions were detected: $\mathrm{C}_{2}{ }_{9} \mathrm{H}_{50} \mathrm{O}_{2}$ and $\mathrm{C}_{n} \mathrm{H}_{2 n-8} \mathrm{O}$, $\mathrm{C}_{n} \mathrm{H}_{2 n-10} \mathrm{O}$, and $\mathrm{C}_{n} \mathrm{H}_{2 n-12} \mathrm{O}$, all for $n=27-29$. The possible triterpenoidal compounds are of the sereies, $\mathrm{C}_{n} \mathrm{H}_{2 n-10}$, ranging from $n=29.33$ and maximizing at $n=$ 32. Only two fragment ions probably derived from the steroidal or triterpenoidal series are above the background: $\mathrm{C}_{19} \mathrm{H}_{27}$ at $\mathrm{m} / \mathrm{e} 255$ and $\mathrm{C}_{19} \mathrm{H}_{27} \mathrm{O}$ at $\mathrm{m} / \mathrm{e} 271$ (Structure XII). Carboxylic acids (probably as the methyl esters - 
Simoneit et al., 1973), $\mathrm{C}_{n} \mathrm{H}_{2 n} \mathrm{O}_{2}$, were present from $n=$ 3-18 as very minor components.

The GC/MS data (cf. Figure 17 and Table 4) indicate mainly alkanes, $\mathrm{C}_{n} \mathrm{H}_{2 n+2}$, for $n=16-33$, exhibiting no predominance (cf. Figure 17b), and carboxylic acids (as the methyl esters-Simoneit et al., 1973a) $\mathrm{C}_{n} \mathrm{H}_{2 n} \mathrm{O}_{2}$, for $n=13-30$, exhibiting an even/odd predominance and maximizing at $n=18$ (cf. Figure $17 \mathrm{c}$ ). The isoprenoid 6,10, 14-trimethylpentadecan-2-one (Structure VI) was detected as a major component of the mixture, but its lower $\mathrm{C}_{13}$ homolog was not found. Steroidal and triterpenoidal compounds were detected in minor amounts usually in spectra of complex mixtures. Contaminants from core tube material (butyl esters) and phthalate esters were minor (cf. Figure $17 \mathrm{~d})$.

The HRMS data of the benzene/methanol solubles (cf. Figure 16) consist mainly of hydrocarbon and $\mathrm{C} / \mathrm{H} \mathrm{O}_{2}$ ions. The hydrocarbons of the series $\mathrm{C}_{n} \mathrm{H}_{2 n+2}$ to $\mathrm{C}_{n} \mathrm{H}_{2 n-16}$ range from $n=3-35$, with significantly fewer homologs being detected. The major oxygenated species are carboxylic acids (probably as the methyl esters - Simoneit et al., in press), $\mathrm{C}_{n} \mathrm{H}_{2 n} \mathrm{O}_{2}$, for $n=3-31$. Some of the same steroidal and triterpenoidal components that were found in the heptane/ether fraction were also present here. Contaminants such as butyl esters and phthalates were minor.

\section{Site 134}

The GC traces of the extract fractions from Sample 13-134-5-2, 77-79 $\mathrm{cm}$ are shown in Figure 18. The small amount of heptane/ether extract only allowed confirmation by GC/MS that the major peak in the GC trace is dioctyl 2,3-dimethylsuccinate (Structure IX) and the minor peaks are mainly alkanes, $\mathrm{C}_{n} \mathrm{H}_{2 n+2}$, ranging from $n=17-31$ with an odd/even predominance and maximum at $n=29$. The benzene/methanol fraction is under further analysis.

\section{Leg 14 Addenda}

In the GC/MS data of some of the Leg 14 samples, we reported as significant component as an unknown of probable molecular weight 250 (Simoneit et al., 1973b). On reexamining the data, the unknown was identified as 6,10,14-trimethylpentadecan-2-one (Structure VI). the relevant data, i.e., $\mathrm{m} / \mathrm{e} 58$ sum plots and mass spectra, are shown in Figures 19 and 20. The Oligocene Sample 14-138-2-6, 12-13 cm scan 120 spectrum (cf. Figure 19b); the middle Cretaceous Sample 14-138-6-3, 49-50 cm scan 106 spectrum (cf. Figure 19e); and the two upper Cretaceous Samples 14-144A-5-1, 114-116 cm scan 99 spectrum (cf. Figure 20b) and 14-144A-6-1, 100-101 cm scan 120 spectrum (cf. Figure 20d) all fit the fragmentation pattern of the standard compound (Cox, 1971). The GC retention times of the compound in each mixture fit for the elution of 6,10,14-trimethylpentadecan-2-one.

The $\mathrm{C}_{13}$ homolog of this isoprenoidal ketone was also confirmed in some of these samples. The best mass spectrum of 6,10-dimethylundecan-2-one (Structure XV) was indicated by the lower peak in the m/e 58 sum plot of Sample 14-138-6-3, 49-50 cm, the scan 30 spectrum (cf. Figure 19d).

\section{DISCUSSION AND CONCLUSIONS}

The sample suite from Legs 12 and 13 is quite unique in its varied organic constituents. It is completely different in compound distributions and types from the Pacific Ocean sediments examined (Simoneit and Burlingame, 1971a,b; 1972a,b). The alkane and carboxylic acid distribution histograms for the Leg 12 samples are shown in Figure 21. The general alkane abundance patterns and strong odd/even predominance are similar to those of samples from the Gulf of Mexico (Simoneit and Burlingame, 1973; Simoneit at al., in press) and indicate a terrigenous input component to these North Atlantic Ocean sediments. The acid distributions (even/odd predominance) appear to be about half marine and half terrigenous in derivation (Simoneit and Burlingame, in preparation). Of special interest is the presence of the isoprenoidal ketone 6 10,14-trimethylpentadecan-2-one (Structure VI) in both samples. This compound is probably derived from phytol or possibly chlorophyll directly by oxidative diagenesis. When phytol is chemically oxidized, the major product is 6,10,14-trimethylpentadecan-2-one (Cox, 1971). The presence of a compound of composition $\mathrm{C}_{40} \mathrm{H}_{74}$ at m/e 554 in Sample 12-114-6-5, 80-140 cm should also be noted. Its possible structure is $m$ - or $p$-(4,8,12-trimethyltridecyl1,5,9,13-tetramethyltetradecyl)benzene (Structure VII). This compound may be a diagenetic product from the Diels-Alder dimer of phytadiene, derived from phytol. Phytadienes were detected in large amounts in DSDP samples from the anoxic Cariaco Trench (Site 147 Simoneit et al., in press) and Black Sea core samples (Simoneit, in press). The minor amounts of steroidal and triterpenoidal compounds in these samples are probably marine in derivation, with some terrigenous influx of the higher molecular weight homologs, especially the triterpenoids.

The relatively low amount of solvent extractable material for Sample 12-112-11-4, 10-99 cm (cf. Table 1) indicates that a significant amount of the organic carbon is present as kerogen in this sample. This is also the case for all the Leg 13 samples analyzed.

The alkane and fatty acid distribution histograms for the Pleistocene samples from the Mediterranean Sea are shown in Figure 22. The alkane pattern with its strong odd/even predominance of the Site 128 samples (cf. Figure 22a, and b) is skewed to the higher weight homologs, indicating a terrigenous input source. The carboxylic acids, which exhibit a strong even/odd predominance, are bimodal with maxima at $\mathrm{C}_{18}$ and $\mathrm{C}_{22}$. The lower weight homologs are due to marine input, and the higher weight homologs are probably derived from terrigenous material. This same type of acid distribution is found for Sample 13-130-1-2, 123-125 cm (cf. Figure 22c). The alkanes for that sample, however, are distributed quite oppositely. They maximize at $\mathrm{C}_{19}$ with essentially no predominance. The higher weight homologs $\left(>\mathrm{C}_{27}\right)$ are minor, but they do exhibit an odd/even predominance. This indicates that the major source of the organic matter in this sample is marine, analogous to the Leg 14 samples (Simoneit et al., 1973b). Steroidal and triterpenoidal components were minor and 
TABLE 4

Major Components of the Heptane-Ether Soluble Extracts from Core Samples of DSDP Leg 13, Determined by GC/MS

\begin{tabular}{|c|c|c|c|c|}
\hline \multirow[b]{3}{*}{ Compound Name } & & & \multicolumn{2}{|c|}{ Samplea } \\
\hline & & & $\begin{array}{l}13-128-3-4 \\
122-124 \mathrm{~cm}\end{array}$ & $\begin{array}{l}13-130-1-2 \\
122-125 \mathrm{~cm}\end{array}$ \\
\hline & \multicolumn{2}{|c|}{$\begin{array}{l}\text { Composition and } \\
\text { Molecular Weight }\end{array}$} & $\begin{array}{l}\text { Spectrum Scan No. } \\
\text { (cf. Fig. 9a) }\end{array}$ & $\begin{array}{l}\text { Spectrum Scan No. } \\
\text { (cf. Fig. 17a) }\end{array}$ \\
\hline Diethyl phthlateb & $\mathrm{C}_{12} \mathrm{H}_{14} \mathrm{O}_{4}$ & 222 & 81 & 62 \\
\hline $\begin{array}{l}\text { 6,10-dimethylundecan- } \\
\text { 2-one }\end{array}$ & $\mathrm{C}_{13} \mathrm{H}_{26} \mathrm{O}$ & 198 & 93 & n.d. \\
\hline Hexadecane ${ }^{c}$ & $\mathrm{C}_{16} \mathrm{H}_{34}$ & 226 & 94 & 72 \\
\hline Methyl tridecanoate & $\mathrm{C}_{14} \mathrm{H}_{28} \mathrm{O}_{2}$ & 228 & n.d. & 75 \\
\hline Heptadecane & $\mathrm{C}_{17} \mathrm{H}_{36}$ & 240 & 97 & 83 \\
\hline Methyl myristate & $\mathrm{C}_{15} \mathrm{H}_{30} \mathrm{O}_{2}$ & 242 & n.d. & 84 \\
\hline Octadecane & $\mathrm{C}_{18} \mathrm{H}_{38}$ & 254 & 101 & 89 \\
\hline Methyl pentadecanoate & $\mathrm{C}_{16} \mathrm{H}_{32} \mathrm{O}_{2}$ & 256 & 102 & 91 \\
\hline $\begin{array}{l}\text { 6,10,14-trimethyl- } \\
\text { pentadecan-2-one }\end{array}$ & $\mathrm{C}_{18} \mathrm{H}_{36} \mathrm{O}$ & 268 & 103 & 94 \\
\hline Phy tane & $\mathrm{C}_{20} \mathrm{H}_{42}$ & 282 & 105 & n.d. \\
\hline Nonadecane & $\mathrm{C}_{19} \mathrm{H}_{40}$ & 268 & 106 & 95 \\
\hline Methyl palmitate & $\mathrm{C}_{17} \mathrm{C}_{34} \mathrm{O}_{2}$ & 270 & 107 & 96 \\
\hline Dibutyl phthalate ${ }^{b}$ & $\mathrm{C}_{16} \mathrm{H}_{22} \mathrm{O}_{4}$ & 278 & 108 & 97 \\
\hline Eicosane & $\mathrm{C}_{20} \mathrm{H}_{42}$ & 282 & 110 & 102 \\
\hline Methyl margarate & $\mathrm{C}_{18} \mathrm{H}_{36} \mathrm{O}_{2}$ & 284 & 111 & 103 \\
\hline Dibutyl azelated & $\mathrm{C}_{17} \mathrm{H}_{32} \mathrm{O}_{4}$ & 300 & n.d. & 105 \\
\hline Heneicosane & $\mathrm{C}_{21} \mathrm{H}_{44}$ & 296 & 115 & 107 \\
\hline Methyl stearate & $\mathrm{C}_{19} \mathrm{H}_{38} \mathrm{O}_{2}$ & 298 & 116 & 109 \\
\hline Dibutyl sebacated & $\mathrm{C}_{18} \mathrm{H}_{34} \mathrm{O}_{4}$ & 314 & 117 & n.d. \\
\hline Docosane & $\mathrm{C}_{22} \mathrm{H}_{46}$ & 310 & 119 & 112 \\
\hline Methyl nonadecanoate & $\mathrm{C}_{20} \mathrm{H}_{40} \mathrm{O}_{2}$ & 312 & 120 & 114 \\
\hline Tricosane & $\mathrm{C}_{23} \mathrm{H}_{48}$ & 324 & 123 & 117 \\
\hline Methyl arachidate & $\mathrm{C}_{21} \mathrm{H}_{42} \mathrm{O}_{2}$ & 326 & 124 & 119 \\
\hline Tetracosane & $\mathrm{C}_{24} \mathrm{H}_{50}$ & 338 & 128 & 122 \\
\hline $\begin{array}{l}\text { Dicotyl 2,3-dimethyl } \\
\text { succinated }^{\mathrm{d}}\end{array}$ & $\mathrm{C}_{22} \mathrm{H}_{42} \mathrm{O}_{4}$ & 370 & n.d. & 123 \\
\hline Methyl heneicosanoate & $\mathrm{C}_{22} \mathrm{H}_{44} \mathrm{O}_{2}$ & 340 & 128 & 124 \\
\hline Pentacosane & $\mathrm{C}_{25} \mathrm{H}_{52}$ & 352 & 132 & 127 \\
\hline Methyl behenate & $\mathrm{C}_{23} \mathrm{H}_{46} \mathrm{O}_{2}$ & 354 & 132 & 129 \\
\hline Dioctyl phthalate ${ }^{b}$ & $\mathrm{C}_{24} \mathrm{H}_{38} \mathrm{O}_{4}$ & 390 & 133 & 131 \\
\hline Hexacosane & $\mathrm{C}_{26} \mathrm{H}_{54}$ & 366 & 136 & 132 \\
\hline Methyl tricosanoate & $\mathrm{C}_{24} \mathrm{H}_{48} \mathrm{O}_{2}$ & 368 & 137 & 134 \\
\hline Heptacosane & $\mathrm{C}_{27} \mathrm{H}_{56}$ & 380 & 141 & 136 \\
\hline Methyl lignocerate & $\mathrm{C}_{25} \mathrm{H}_{50} \mathrm{O}_{2}$ & 382 & 142 & 138 \\
\hline Octacosane & $\mathrm{C}_{28} \mathrm{H}_{58}$ & 394 & 147 & 141 \\
\hline Methyl pentacosanoate & $\mathrm{C}_{26} \mathrm{H}_{52} \mathrm{O}_{2}$ & 396 & 148 & 143 \\
\hline Nonacosane & $\mathrm{C}_{29} \mathrm{H}_{60}$ & 408 & 154 & 146 \\
\hline Methyl cerotate & $\mathrm{C}_{27} \mathrm{H}_{54} \mathrm{O}_{2}$ & 410 & 155 & 148 \\
\hline Sterane & $\mathrm{C}_{29} \mathrm{H}_{52}$ & 400 & 157 & 151 \\
\hline Triacontane & $\mathrm{C}_{30} \mathrm{H}_{62}$ & 422 & 163 & 153 \\
\hline Methyl heptacosanoate & $\mathrm{C}_{28} \mathrm{H}_{56} \mathrm{O}_{2}$ & 424 & n.d. & 155 \\
\hline Sterane & $\mathrm{C}_{30} \mathrm{H}_{54}$ & 414 & 166 & n.d. \\
\hline Hentriacontane & $\mathrm{C}_{31} \mathrm{H}_{64}$ & 436 & 174 & 162 \\
\hline
\end{tabular}




\begin{tabular}{|c|c|c|c|c|}
\hline \multirow[b]{3}{*}{ Compound Name } & & & \multicolumn{2}{|c|}{ Samplea } \\
\hline & & & $\begin{array}{l}13-128-3-4 \\
122-124 \mathrm{~cm}\end{array}$ & $\begin{array}{l}13-130-1,2 \\
122-125 \mathrm{~cm}\end{array}$ \\
\hline & \multicolumn{2}{|c|}{$\begin{array}{l}\text { Composition and } \\
\text { Molecular Weight }\end{array}$} & $\begin{array}{l}\text { Spectrum Scan No. } \\
\text { (cf. Fig. 9a) }\end{array}$ & $\begin{array}{l}\text { Spectrum Scan No. } \\
\text { (cf. Fig. 17a) }\end{array}$ \\
\hline Triterpane & $\mathrm{C}_{30} \mathrm{H}_{52}$ & 412 & 175 & n.d. \\
\hline Methyl octacosanoate & $\mathrm{C}_{29} \mathrm{H}_{58} \mathrm{O}_{2}$ & 438 & 176 & 163 \\
\hline Dotriacontane & $\mathrm{C}_{32} \mathrm{H}_{66}$ & 450 & 189 & 171 \\
\hline Methyl nonacosanoate & $\mathrm{C}_{30} \mathrm{H}_{60} \mathrm{O}_{2}$ & 452 & n.d. & 173 \\
\hline Tritriacontane & $\mathrm{C}_{33} \mathrm{H}_{68}$ & 464 & 208 & 182 \\
\hline Methyl triacontanoate & $\mathrm{C}_{31} \mathrm{H}_{62} \mathrm{O}_{2}$ & 466 & n.d. & 183 \\
\hline
\end{tabular}

$a_{\text {n.d. }}=$ not detected.

bProbably sample vial cap contamination.

'The configurations of the alkanes and acids ( $n-$, iso-, or anteiso-) are not specified, but they are probably predominantly normal.

dProbably core tube contamination.

probably of both marine and terrigenous derivation. The isoprenoidal ketones discussed above were also present in these samples. The Site 128 samples contained mainly 6,10,14-trimethylpentadecan-2-one (Structure VI) and minor amounts of 6,10,14-trimethylpentadecan-2-one (Structure VI) and minor amounts of 6,10-dimethylundecan-2-one (Structure XV), whereas the Site 130 sample contained only the $\mathrm{C}_{18}$ homolog.

These ketones were also identified in some samples from DSDP Leg 14, where the $\mathrm{C}_{18}$ compound (Structure VI) was the most abundant homolog, and the $\mathrm{C}_{13}$ ketone (Structure XV) was found in minor amounts in only two samples. The maximum samples age where the ketones have been identified is upper Cretaceous (Leg 14 - Simoneit et al., 1973b), or about $9 \times 10^{7}$ years B.P. Further work is in progress to reexamine other samples for the presence of these compounds, and also model systems (e.g., clay and phytol under acid conditions) are under study to assess whether these ketones are indigenous to the samples or formed during workup.

\section{ACKNOWLEDGMENTS}

We thank Mrs. Ellen Scott for technical assistance, Dr. Robert Cox and Mr. Fred Walls for assistance with GC/MS and Miss Rosalynd Jackson and Dr. James Chang for assistance with high resolution mass spectrometry. The financial support from the Oceanography Section of the National Science Foundation (NSF Grant GA-24214) and from the National Aeronautics and Space Administration (NASA Grant NGL 05-003-003) is gratefully acknowledged.

\section{REFERENCES}

Arpino, P. and Ourisson, G., 1971. Interactions between rock and organic matter. Esterification and transesterification induced in sediments by methanol and ethanol: Anal. Chem., v. 43, p. 1656.

Burlingame, A. L., 1968. Data acquisition, processing and interpretation via coupled high-speed real-time digitial computer and high resolution mass spectrometer systems: Advances in Mass Spectrometry, E. Kendrick, (Ed.), London (The Institute of Petroleum), v. 4, p. 15. 1970. Developments and applications of real-time high resolution mass spectrometry: Recent Developments in Mass Spectroscopy, K. Ogata and T. Hayakawa (Eds.), Tokyo (University of Tokyo Press), p. 104.

Burlingame, A. L., and Smith, D. H., 1968. Automated heteroatomic plotting as an aid to the presentation and interpretation of high resolution mass spectral data: Tetrahedron, v. 24, p. 5749.

Burlingame, A. L., Smith, D. H., Merren, T. O., and Olsen, R. W., 1970. Real-time high resolution mass spectrometry: Computers in Analytical Chemistry, C. H. Orr Orr and J. Norris (Eds.), New York (Plenum Press), v. 4, p. 17.

Chang, J. J., Walls, F. C., Smith, D. H., Simoneit, B. R., and Burlingame, A. L. The LOGOS compound classifier for background corrected low resolution mass spectral data. (in preparation).

Cox, R. E., 1971. Acyclic isoprenoids of geochemical significance: Ph.D. Thesis, University of Bristol, Bristol, England.

Laughton, A. S., Berggren, W. A., Benson, R., Davies, T. A., Franz, U., Musich, L., Perch-Nielsen, K., Ruffman, A., van Hinte, J. E., and Whitmarsh, R. B., 1970. Deep Sea Drilling Project, Leg 12: Geotimes, v. 15, p. 10.

Ryan, W. B. F., Hsü, K. J., Nesteroff, W. D., Pautot, G., Wezel, F. C., Lort, J. M., Cita, M. B., Maync, W., Stradner, H., and Dumitrica, P., 1970. Deep Sea Drilling Project: Leg 13: Geotimes, v. 15, p. 12.

Simoneit, B. R. Organic analyses of the Black Sea Cores: The Black Sea: Geology, Chemistry and Biology, E. T. Degens and D. A. Ross (Eds.), Am. Assoc. Petrol. Geol. Mem. (in press).

Simoneit, B. R. and Burlingame, A. L., 1971a. Some preliminary results on the higher weight hydrocarbons and fatty acids in the Deep Sea Drilling Project Cores, Legs 5-7: Initial Reports of the Deep Sea Drilling Project, Volume VII. Washington (U.S. Government Printing Office), p. 889. 


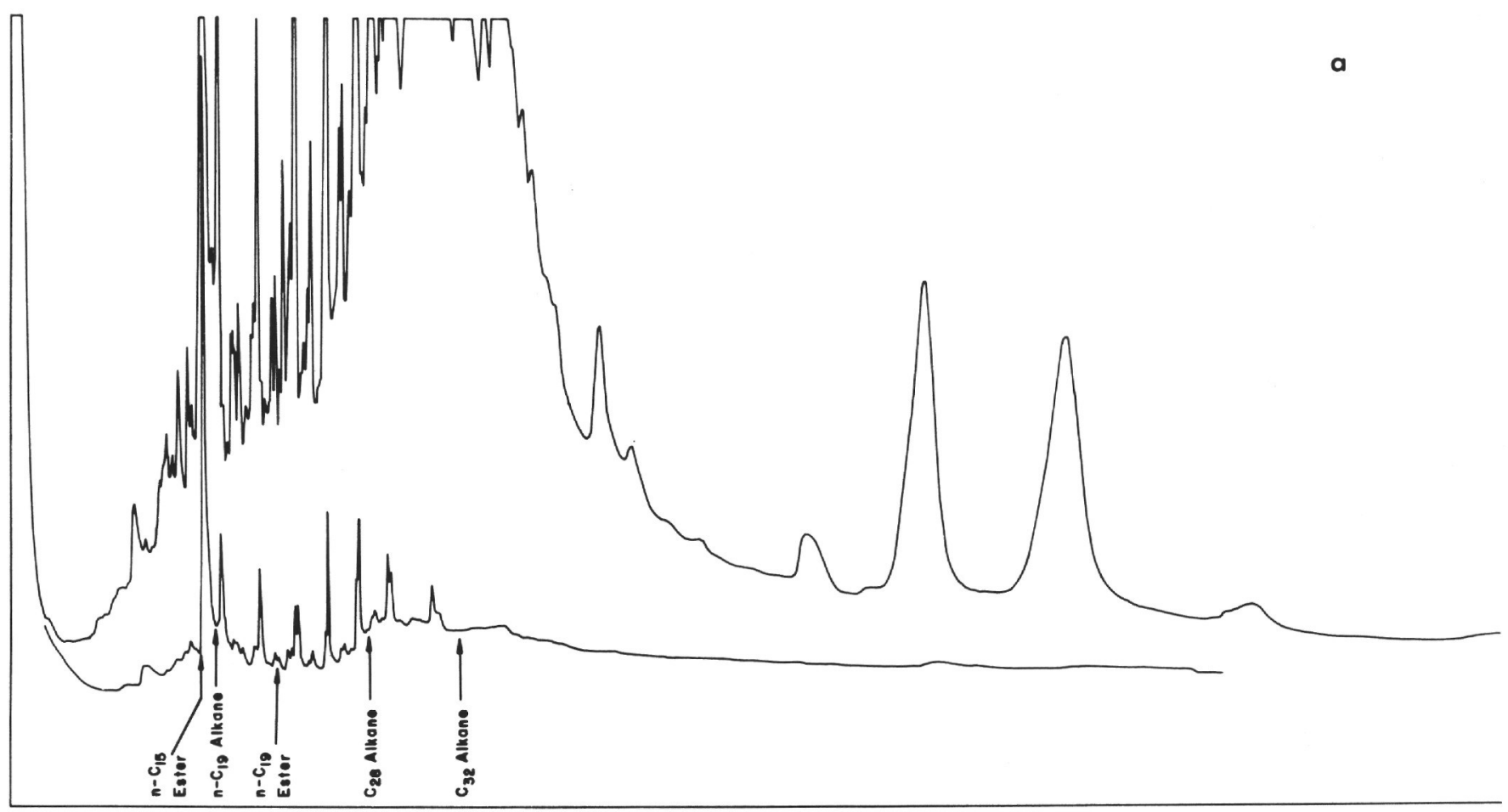

TIME $\longrightarrow$

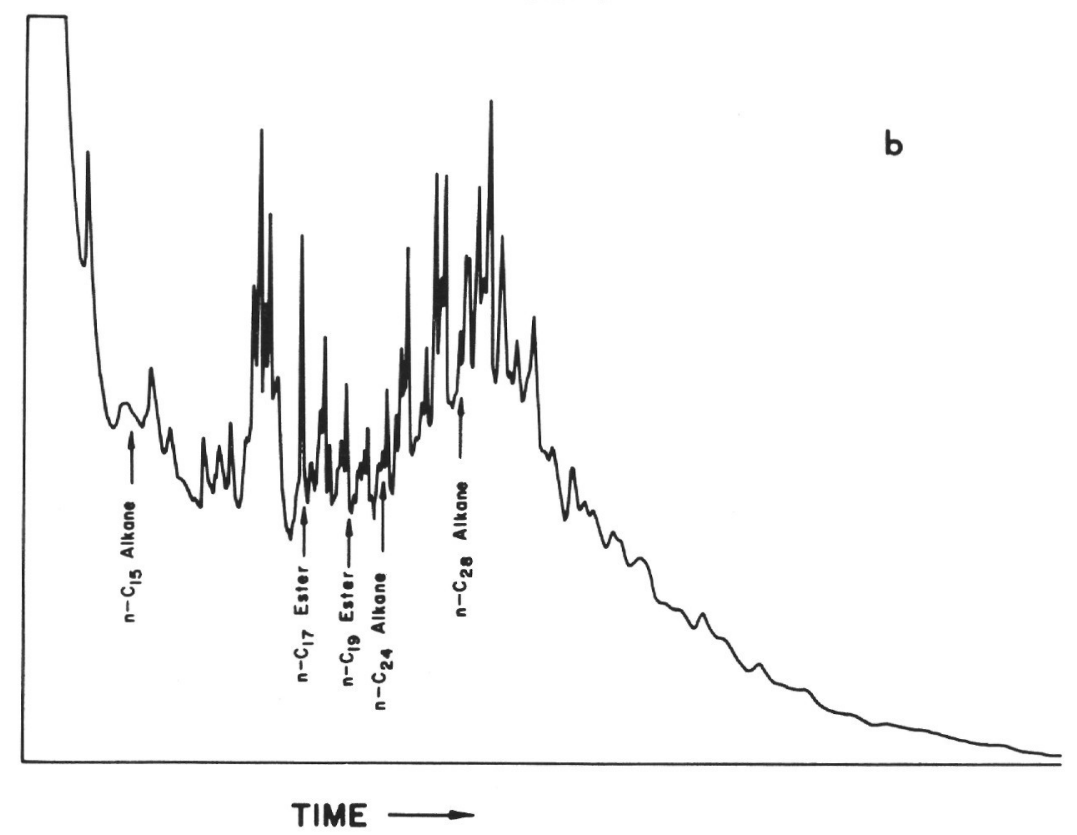

Figure 11. (a) GC trace of the heptane soluble fraction from the exhaustive extract of Sample 13-128-3-5, 38-40 cm, (b) GC trace of the benzene and methanol soluble fraction from the exhaustive extract of Sample 13-128-3-5, 38-40 cm. (GC conditions as cited in Figure 6b.) 
XIII 128-3/5 (30-40Cr) HEPT
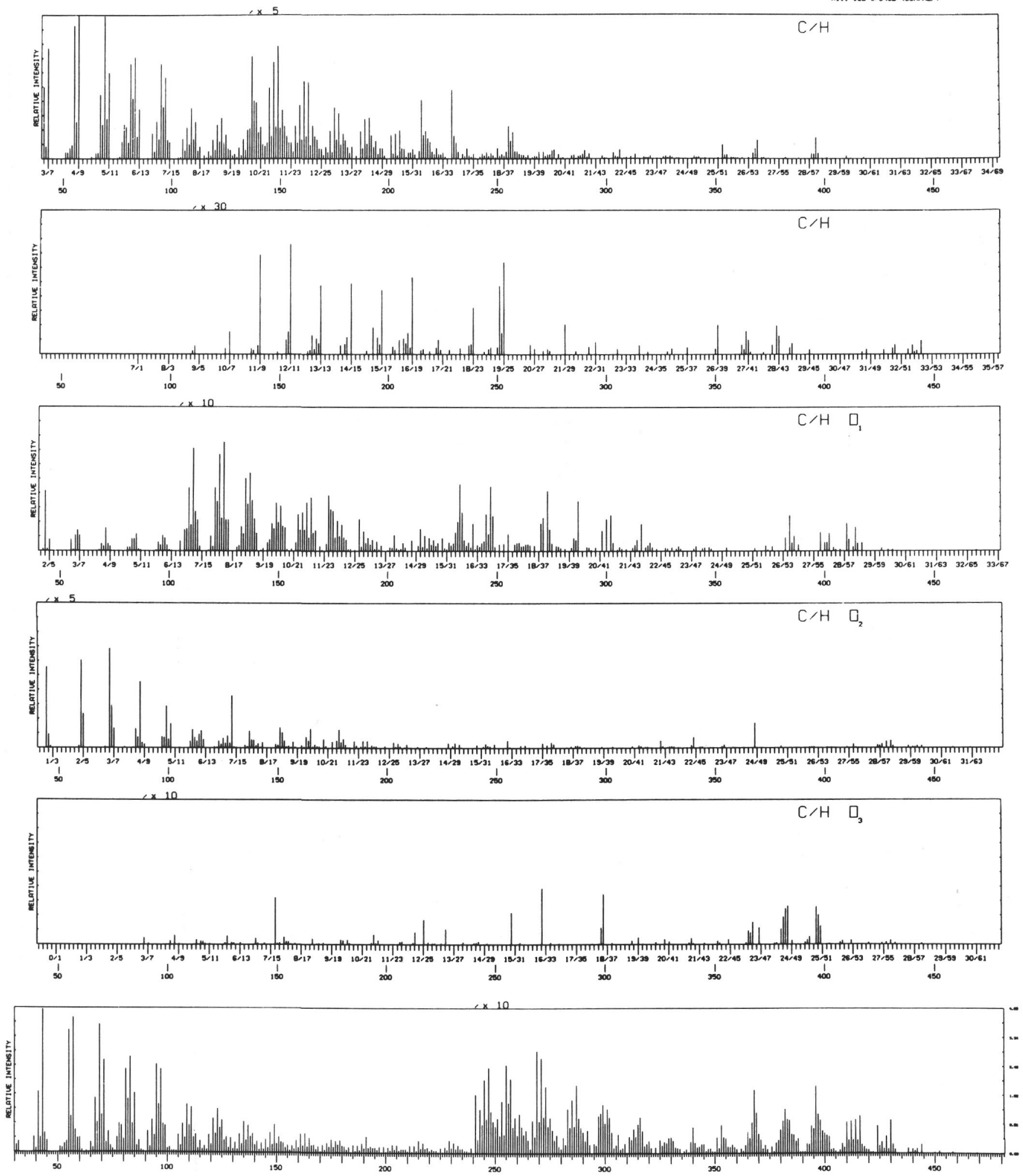

Figure 12. Partial high resolution mass spectrometric data for the heptane soluble fraction from the exhaustive extract of Sample 13-128-3-5, 38-40 cm. 

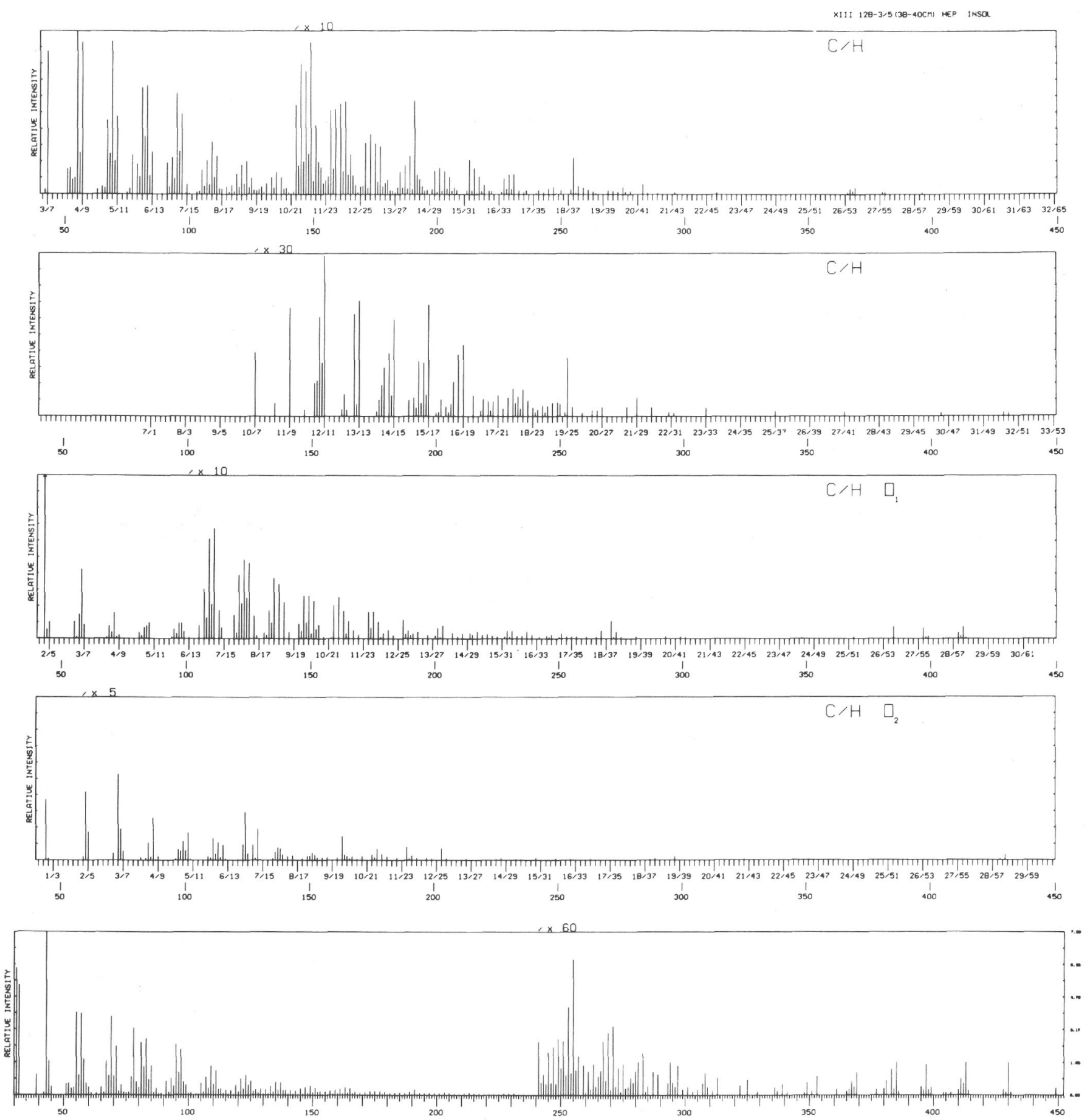

Figure 13. Partial high resolution mass spectrometric data for the benzene and methanol soluble fraction from the exhaustive extract of Sample 13-128-3-5, 38-40 cm. 


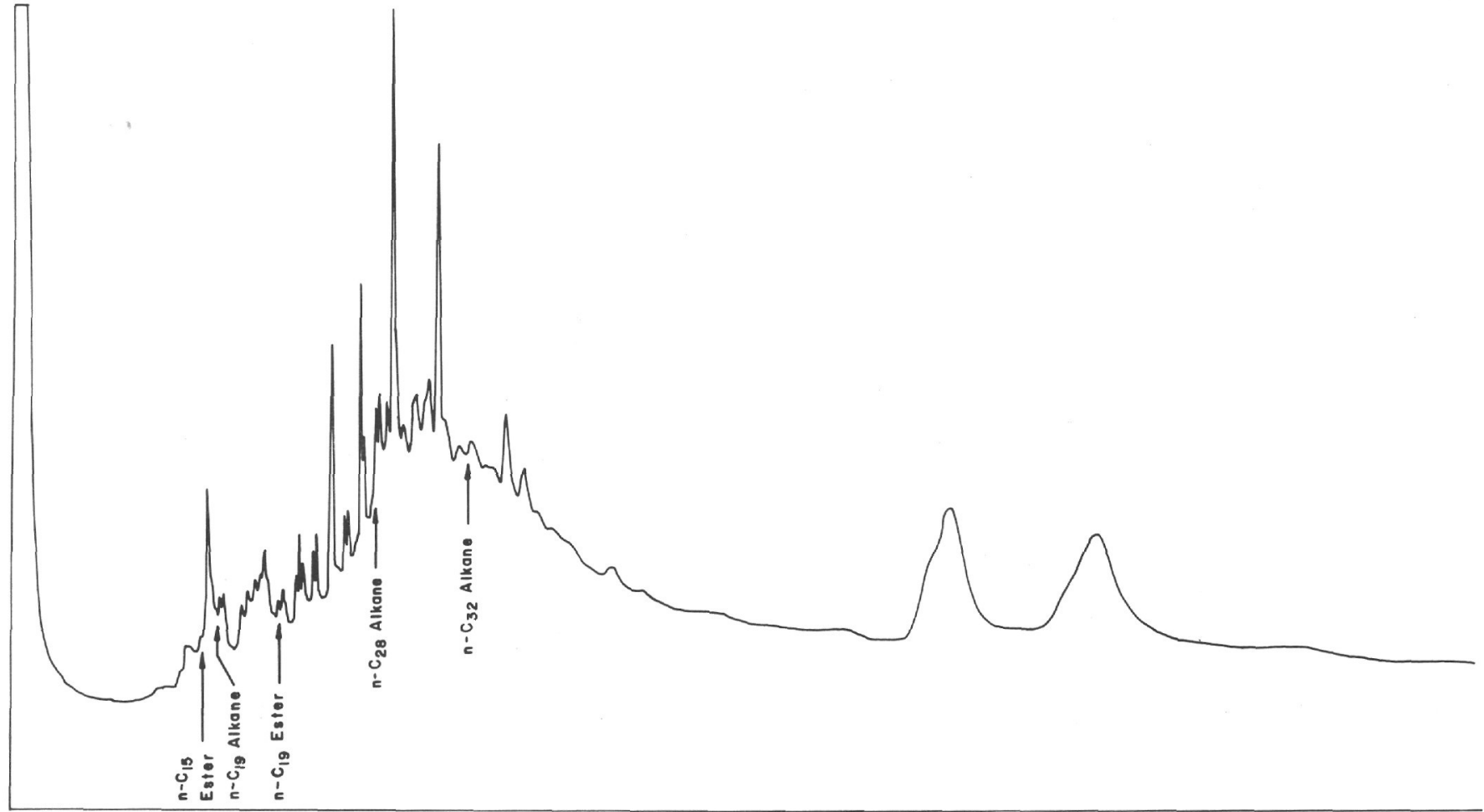

TIME

b

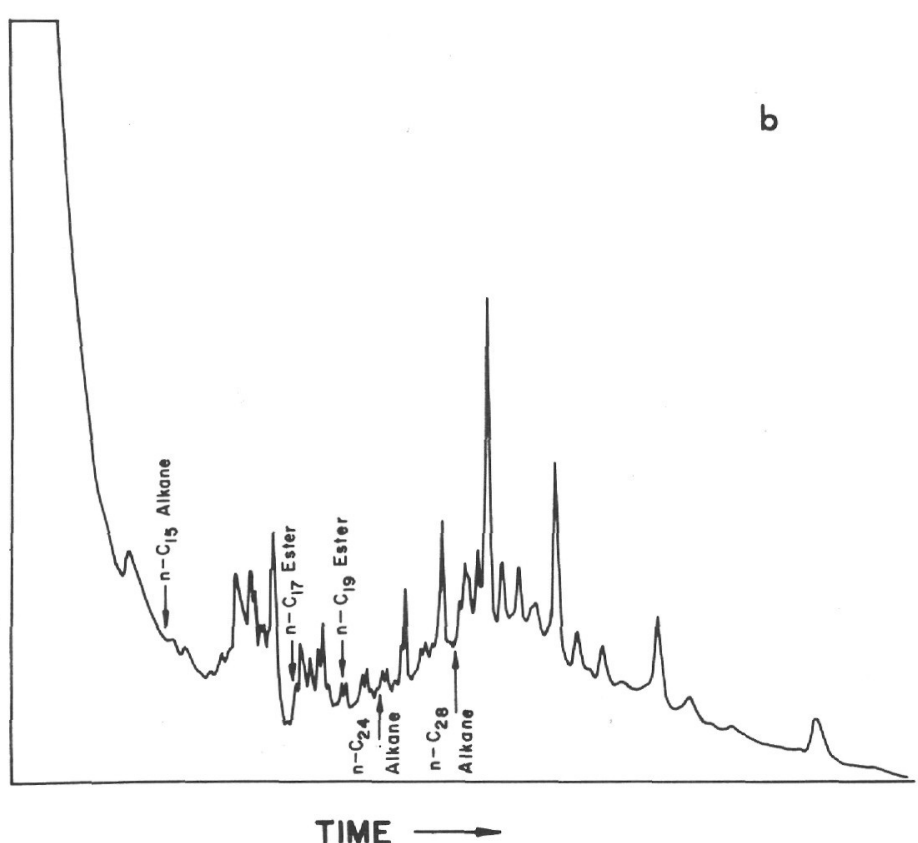

Figure 14. (a) GC trace of the heptane soluble fraction from the exhaustive extract of Sample 13-130-1-2, 123-125 cm, (b) GC trace of the benzene and methanol soluble fraction from the exhaustive extract of Sample 13-130-1-2, 123-125 cm. ( $G C$ conditions as cited in Figure 6b.) 


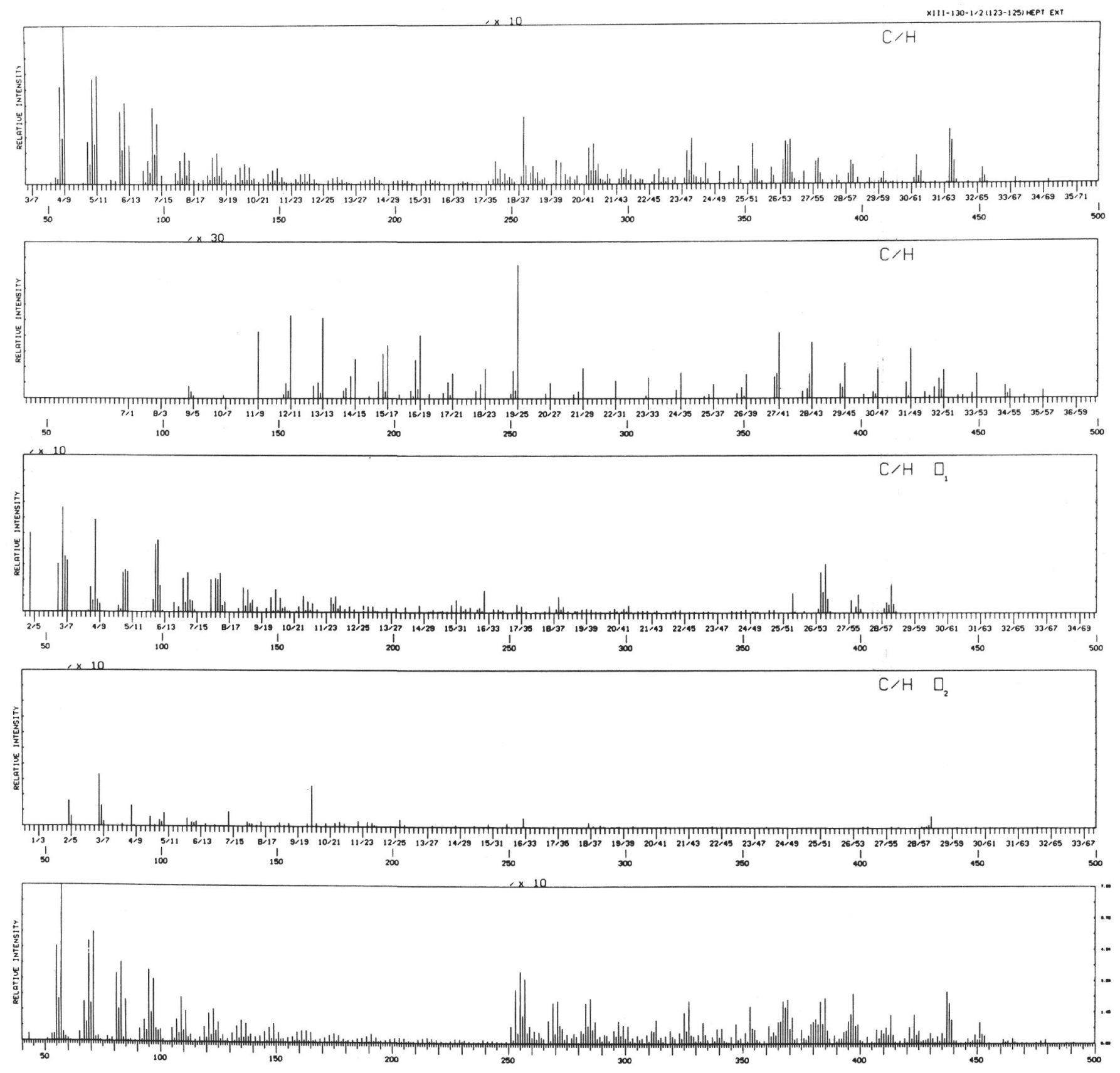

Figure 15. Partial high resolution mass spectrometric data for the heptane soluble fraction from the exhaustive extract of Sample 13-130-1-2, 123-125 cm. 

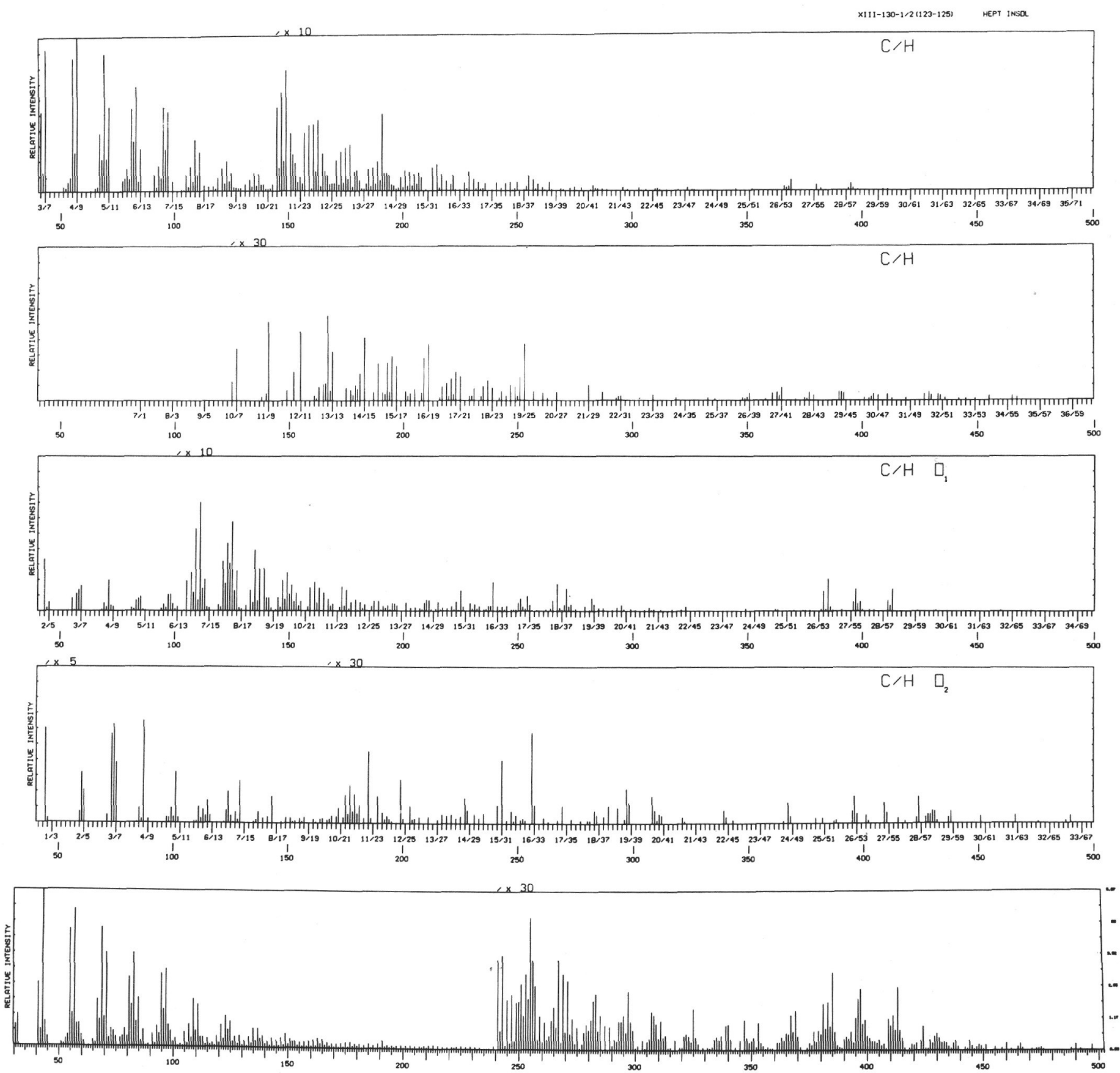

Figure 16. Partial high resolution mass spectrometric data for the benzene and methanol soluble fraction from the exhaustive extract of Sample 13-130-1-2, 123-125 cm. 
ㅇ.
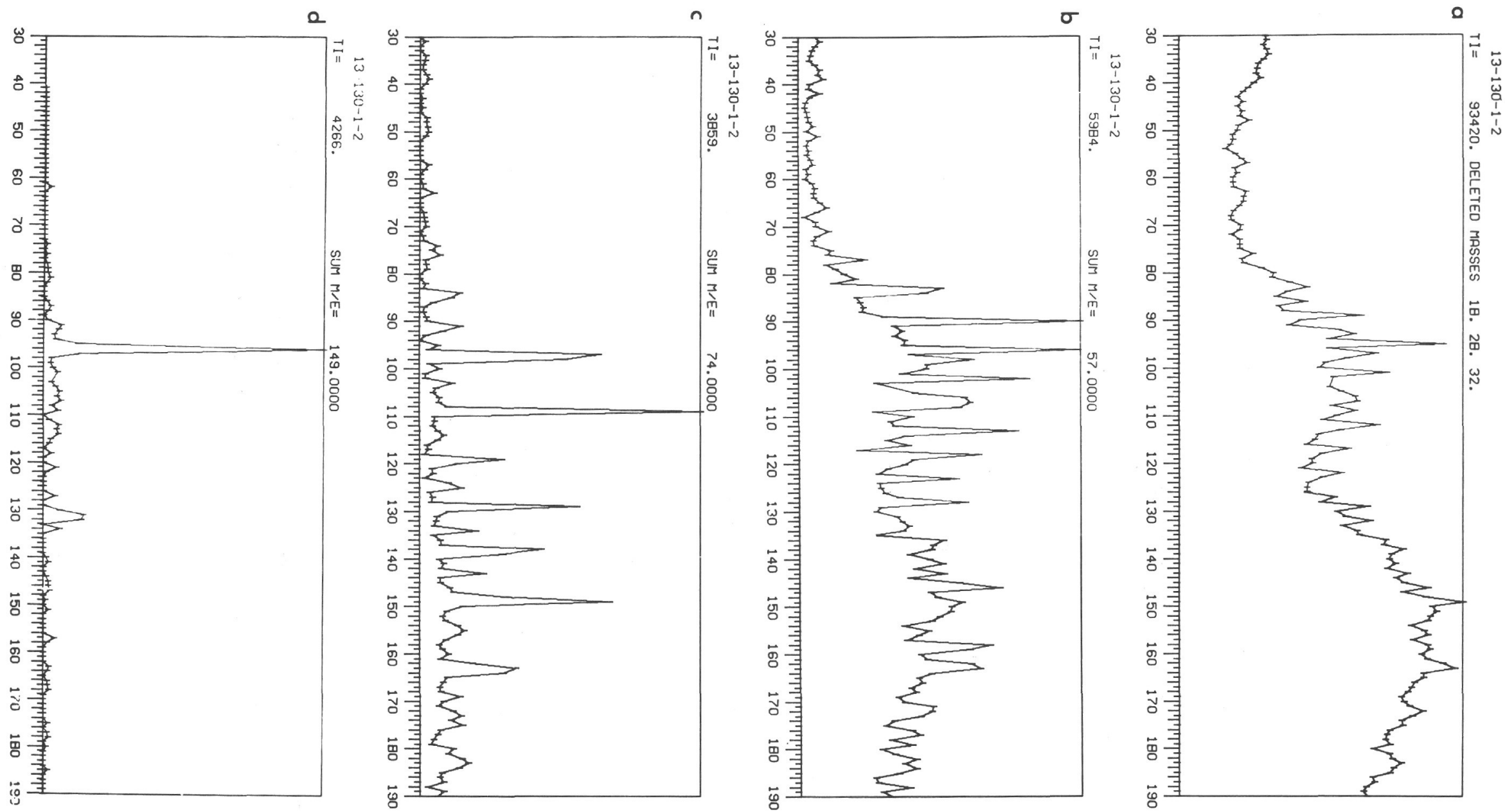

Figure 17. GC/MS data for the total heptane-ether soluble extract fraction from Sample 13-130-1-2, 123-125 cm (GC conditions as cited in Figure 6b). (a) total ionization sum plot, (b) $\mathrm{m} / \mathrm{e} 57$ sum plot, (c) $\mathrm{m} / \mathrm{e} 74$ sum plot, (d) $\mathrm{m} / \mathrm{e} 149$ sum plot. 


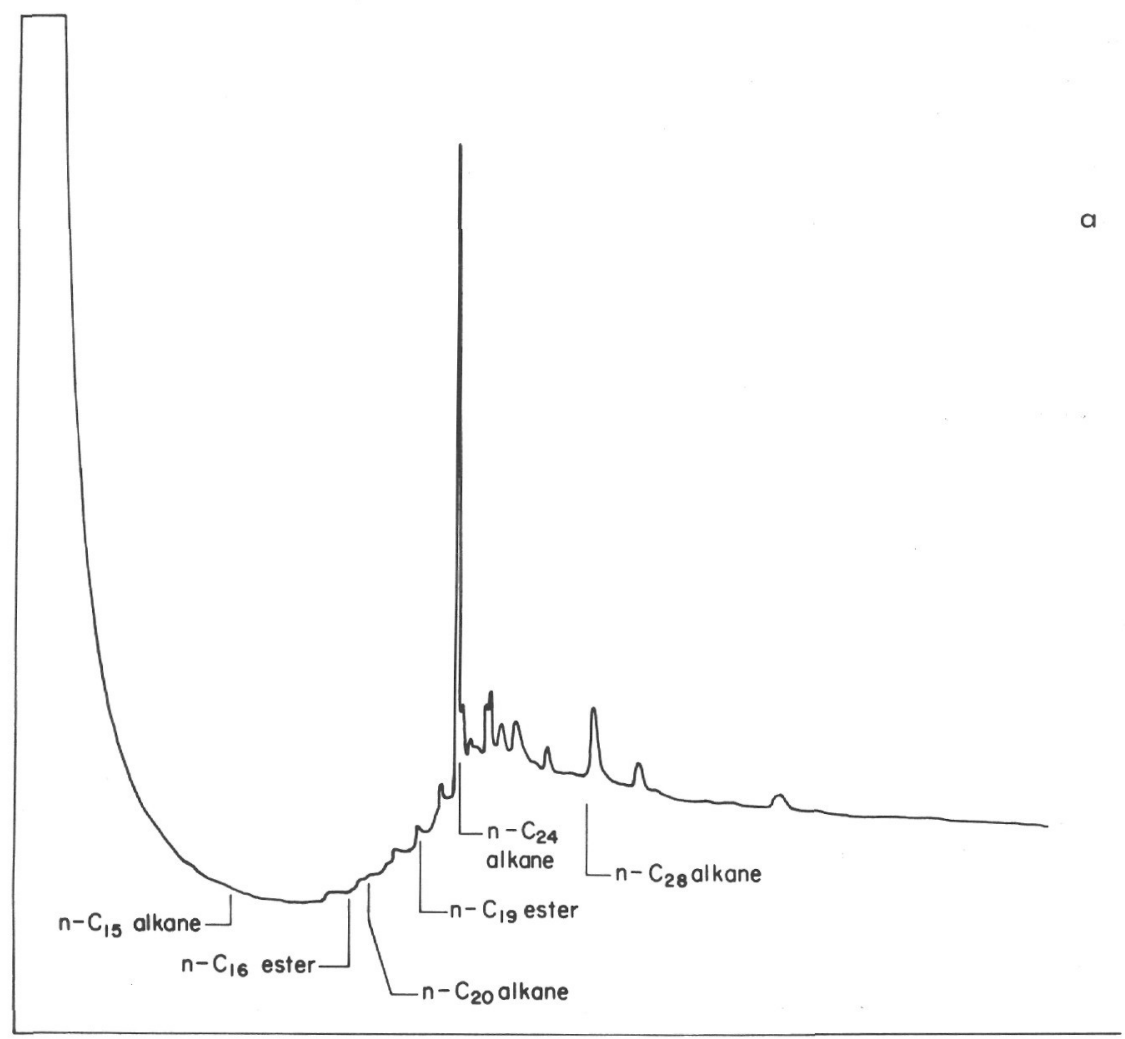

$\mathrm{TIME} \longrightarrow$

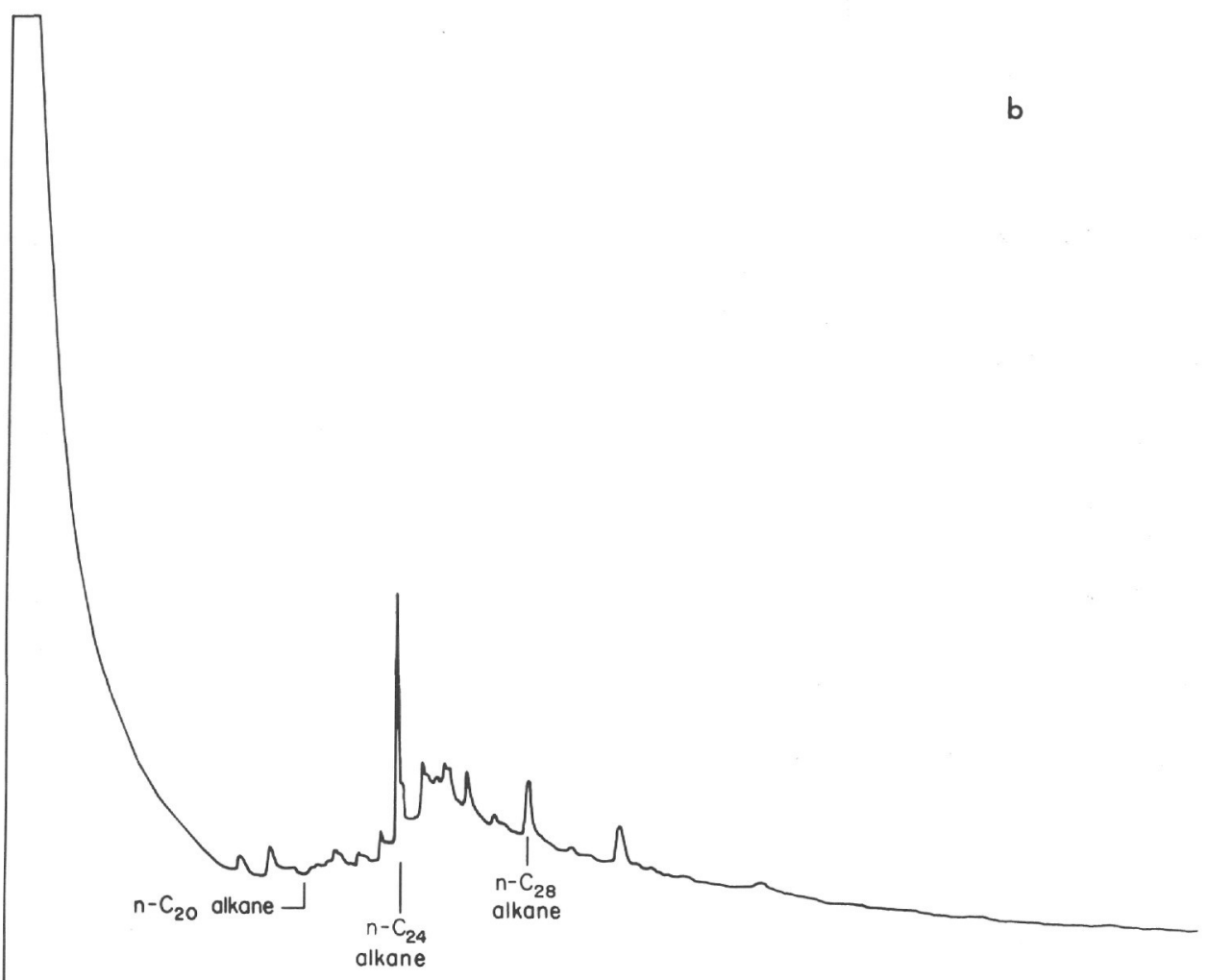

TIME

Figure 18. (a) GC trace of the heptane-ether soluble fraction from the exhaustive extract of Sample 13-134-5-2, 77-79 cm, (b) GC trace of the benzene and methanol soluble fraction from the exhaustive extract of Sample 13-134-5-2, 77-79 cm. (GC conditions as cited in Figure 6b.) 
Q

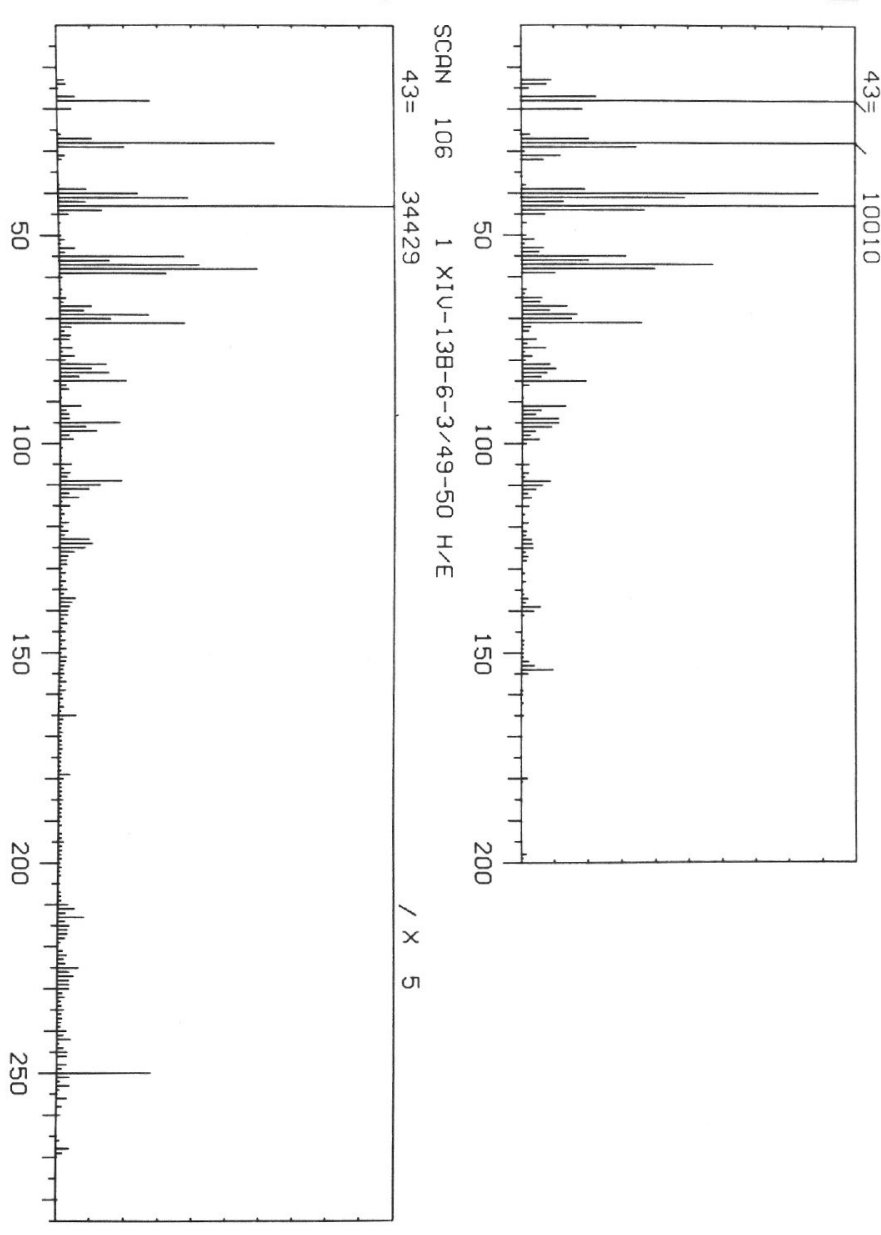

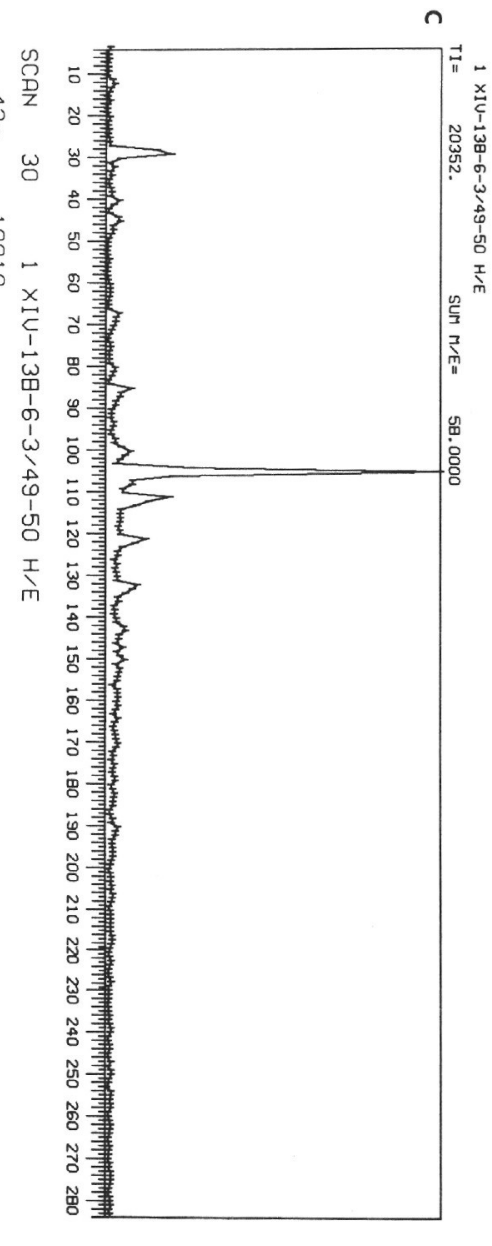

$\sigma$

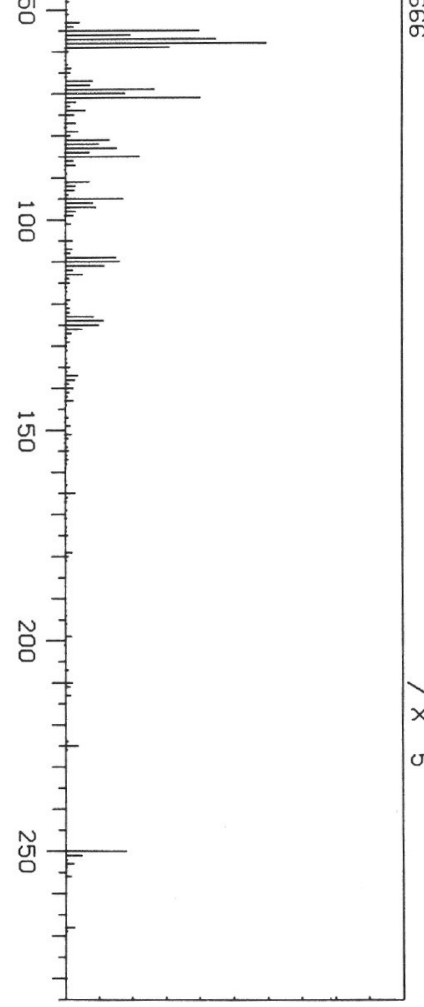

Figure 19. GC/MS data for the total heptane soluble extract from Sample 14-138-2-6, $12-13 \mathrm{~cm}$ (a) m/e 58 sum plot, (b) mass spectrum scan 120 (6,10,14-trimethylpentadecan-2-one, MW 268). GC/MS data for the total heptane soluble extract from Sample 14-138-6-3, 49-50 cm. (c) $\mathrm{m} / \mathrm{e} 58 \mathrm{sum}$ plot, (d) mass spectrum scan 30 (6,10-dimethylundecan-2-one, MW 198), (e) mass spectrum scan 106 (6,10,14-trimethylpentadecan-2-one, MW 268). (GC conditions and total ionization plots cf. Simoneit et al., 1973b.) 


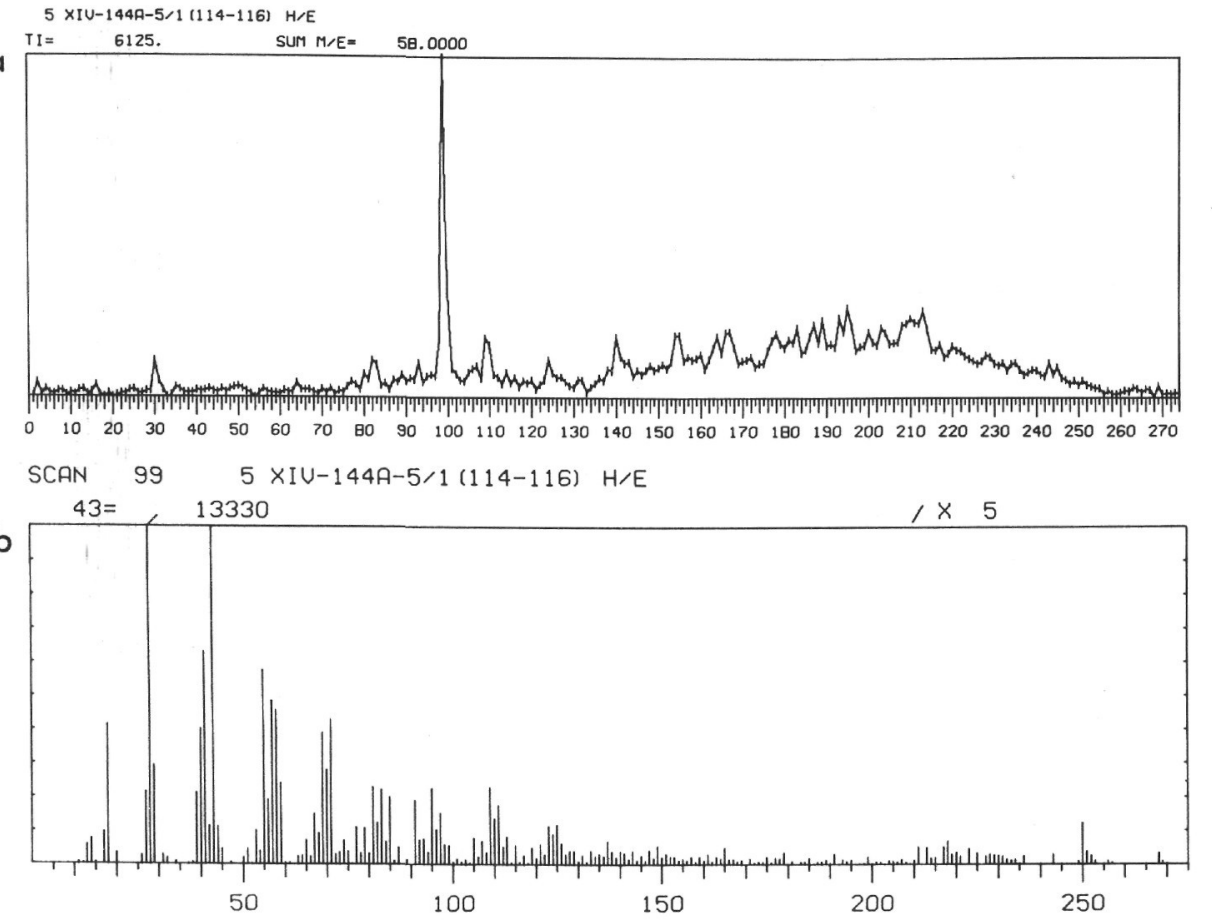

XIV-144A-6/1 (100-101) H-E
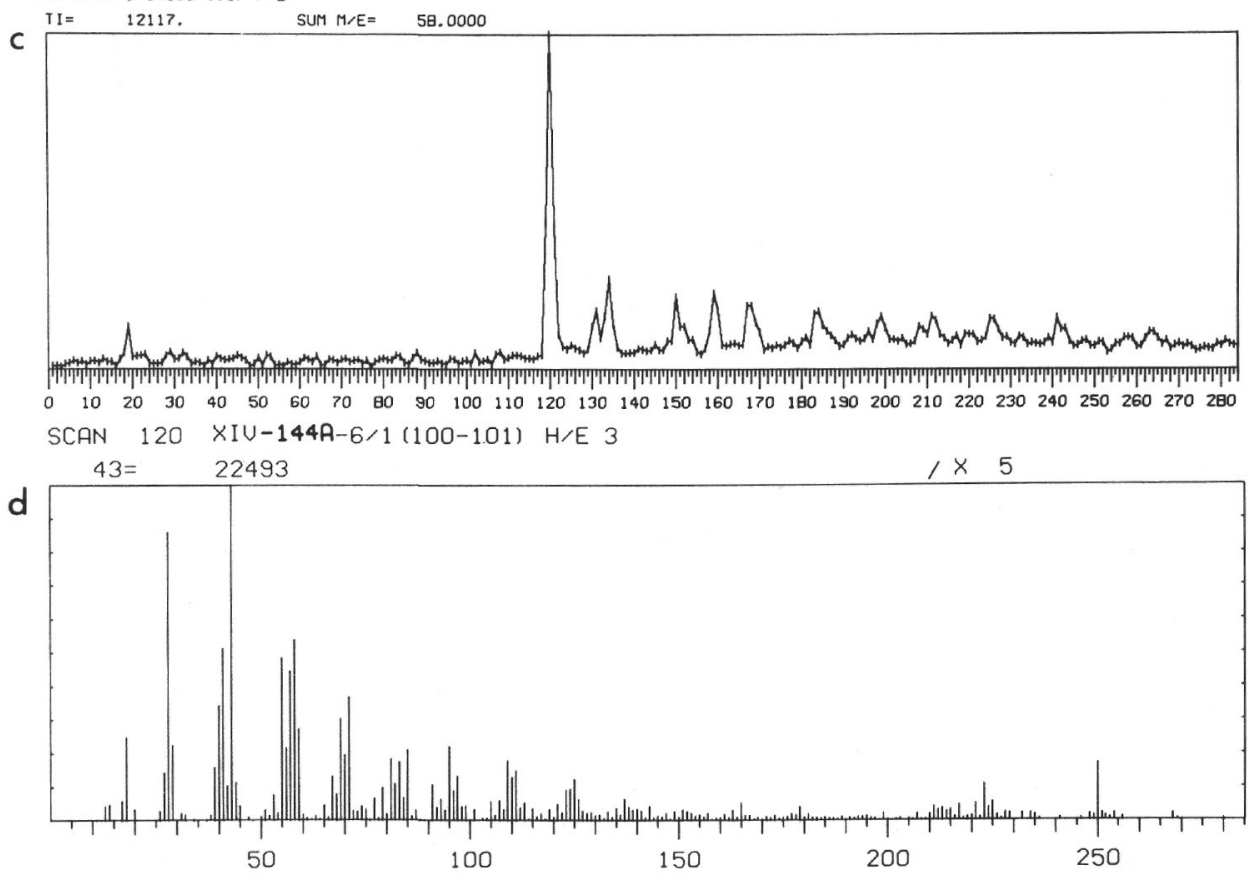

Figure 20. GC/MS data for the total heptane soluble extract from Sample 14-144A-5-1, 114-116 cm. (a) m/e 58 sum plot, (b) mass spectrum scan 99 (6,10,14-trimethylpentadecan-2-one, MW 268). GC/MS data for the total heptane soluble extract from Sample 14-144A-6-1, 100-101 cm. (c) m/e 58 sum plot, (d) mass spectrum scan 120 (6,10,14-trimethylpentadecan-2-one, MW 268). (GC conditions and total ionization plots cf. Simoneit et al., 1973b.) 

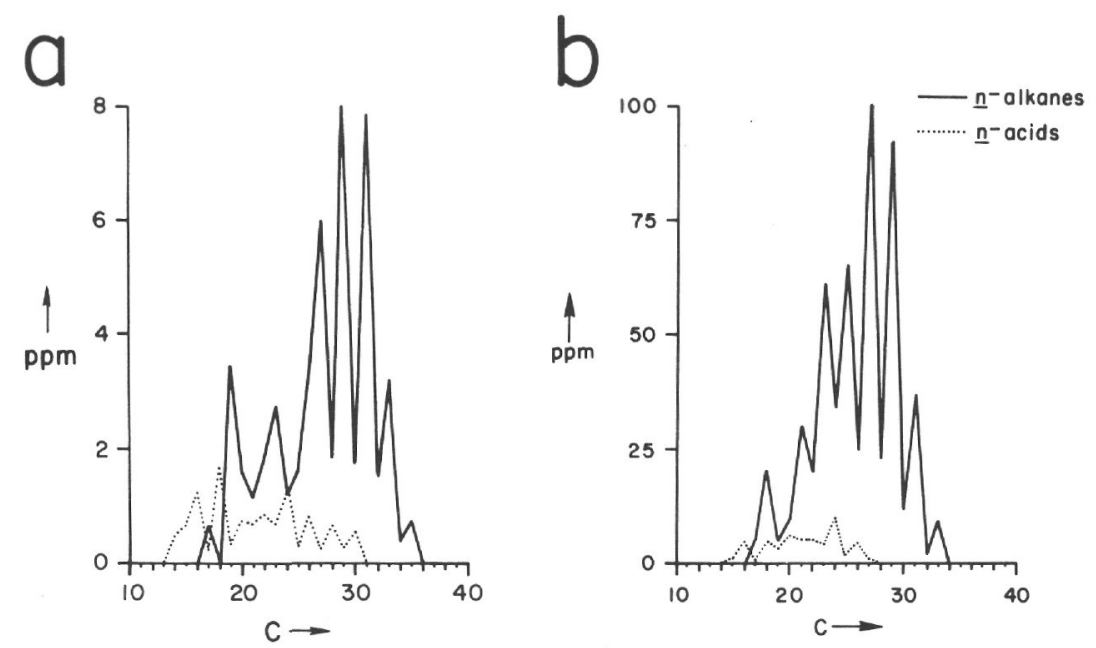

Figure 21. Homologous series distribution histograms for the Leg 12 samples. (a) 12-112-11-4, 10-99 cm, (b) 12-114-5-5, 80-140 cm.
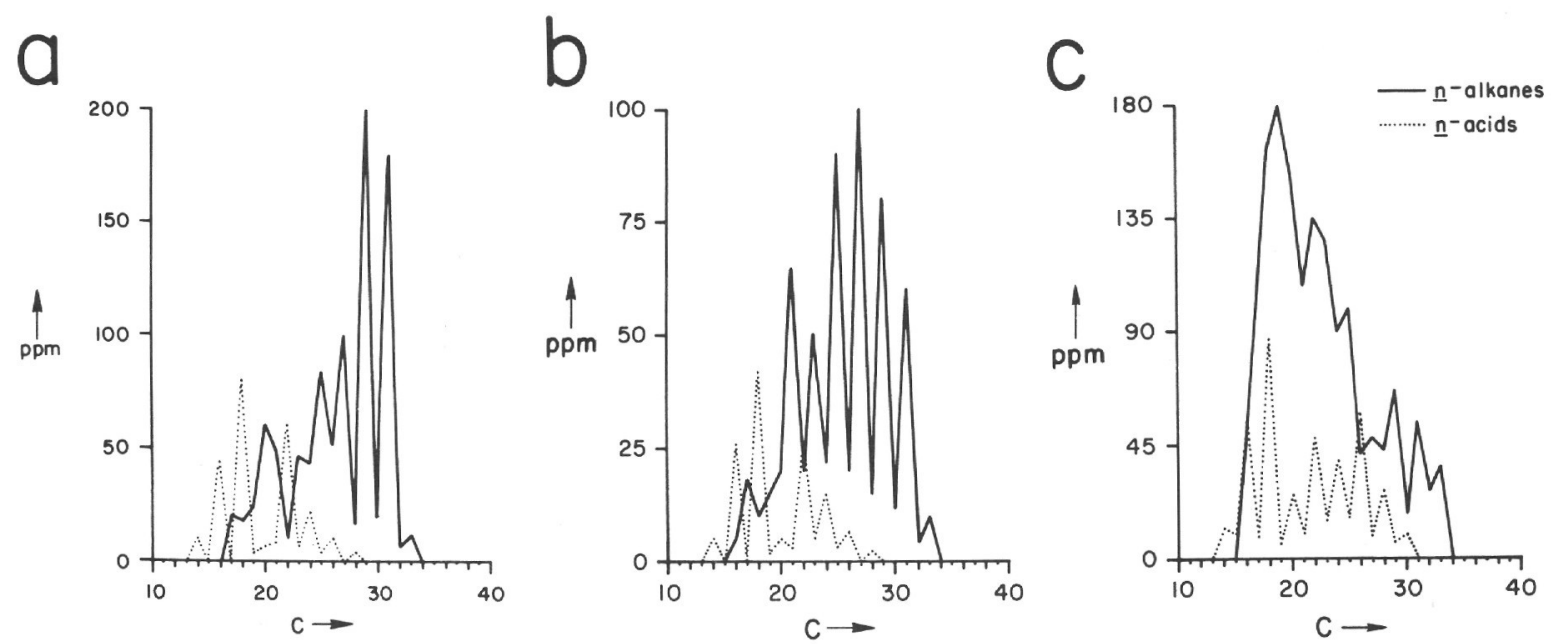

Figure 22. Homologous series distribution histograms for the Leg 13 Samples. (a) 13-128-3-4, 122-124 cm, (b) $13-128-3-5,38-40 \mathrm{~cm}$, (c) $13-130-1-2,123-125 \mathrm{~cm}$.

1971b. Further preliminary results on the higher weight hydrocarbons and fatty acids in the Deep Sea Drilling Project Cores, Legs 5-8: Initial Reports of the Deep Sea Drilling Project, Volume VIII. Washington (U.S. Government Printing Office), p. 873.

, 1972a. Further preliminary results on the higher weight hydrocarbons and fatty acids in the Deep Sea Drilling Project Cores, Leg 9: Initial Reports of the Deep Sea Drilling Project, Volume IX. Washington (U.S. Government Printing Office), p. 869.

1972b. Preliminary organic analyses of the Deep Sea Drilling Project (JOIDES) cores, legs V-IX: Advances in Organic Geochemistry 1971, H. R. von Gaertner and H. Wehner (Eds.), Braunschweig (Pergamon-Vieweg), p. 189.

Organic geochemistry of the DSDP (JOIDES) cores, legs 5-15: (in preparation).

Simoneit, B. R., Howells, W. G., and Burlingame, A. L. Preliminary organic geochemical analyses of the Cariaco Trench Site 147, Deep Sea Drilling Project, Leg 15: Initial Reports of the Deep Sea Drilling Project, Volume XV. Washington (U.S. Government Printing Office)(in press).
Simoneit, B. R., Scott, E. S., and Burlingame, A. L. 1973a. Preliminary organic analyses of the Deep Sea Drilling Project Cores, Leg 10: Initial Reports of the Deep Sea Drilling Project, Volume X. Washington (U.S. Government Printing Office), p. 625.

1973b. Preliminary organic analyses of Deep Sea Drilling Project Cores, Leg 15: Initial Reports of the Deep Sea Drilling Project, Volume XVI. Washington (U.S. Government Printing Office), p. 575.

Simoneit, B. R., Scott, E. S., Howells, W. G., and Burlingame, A. L., 1972. Preliminary organic analyses of the Deep Sea Drilling Project Cores from Leg 11: Initial Reports of the Deep Sea Drilling Project, Volume XI. Washington (U.S. Government Printing Office), p. 1013.

Smith, D. H., 1972. A compound classifier based on computer analysis of low resolution mass spectral data: Geochemical and environmental applications: Anal. Chem. v. 44, p. 536.

Smith, D. H. Olsen, R. W., Walls, F. C., and Burlingame, A. L., 1971. Real-time organic mass spectrometry: LOGOS - a generalized laboratory system for high and low resolution, GC/MS and closed-loop applications: Anal. Chem., v. 43 , p. 1796. 